\title{
SECTORAL PRICE STICKINESS AND INFLATION \\ PERSISTENCE IN POLAND: A TWO-SECTOR \\ DSGE APPROACH*
}

\section{Agnieszka Leszczyńska-Paczesna ${ }^{a}$}

\begin{abstract}
This paper presents a theoretical model that is suitable for the analysis of price-setting hetero-geneity in a small open economy. The model is based on Benigno and LópezSalido's (2006) work and is one of many examples of a dynamic stochastic general equilibrium (DSGE) model that utilizes heterogeneous price stickiness (e.g., Aoki, 2001; Bodenstein et al., 2008). The model allows analyses of a small open economy by extending the existing multisector models using the mechanisms described by Galí and Monacelli (2005). As a result, the model enables monetary policy analyses that take into account existing sectoral differences in the price-setting mechanisms found in an open economy. In the empirical part of the paper, the model is estimated on data for Poland using Bayesian techniques. The results show that the period 1999-2017 saw significant differences in price stickiness and inflation persistence in the sectors that produce food and energy compared with sectors that produce other goods and services.
\end{abstract}

Keywords: DSGE, core inflation, Bayes factor, Bayesian estimation JEL Classification: E30, E32, E37, E40

\section{Introduction}

Previous analyses of individual prices have found significant differences in the level of price stickiness across the production sectors of an economy (Bils and Klenow, 2004; Dhyne et al., 2006). In general, energy and food prices are reported to change much more frequently

a University of Lodz, Faculty of Economics and Sociology, Lodz, Poland Email: agnieszka.leszczynska@uni.lodz.pl

* The research was supported by the National Science Centre in Poland (2014/15/N/HS4/01450). I want to thank Paweł Baranowski for his advice, as well as the two anonymous referees for their insightful comments. All errors remain my responsibility.

1 As reported by Dhyne et al. (2006), the frequencies of consumer price changes in the euro area are as follows: energy products $(78 \%)$, unprocessed food $(28.3 \%)$, processed food $(13.7 \%)$, nonenergy manufactured goods $(9.2 \%)$ and services $(5.6 \%)$. 
than those of other goods and services. ${ }^{1}$ In addition, there are also significant differences in inflation persistence across different types of consumer goods (Bilke, 2005; Lünnemann and Mathä, 2004; Hertel and Leszczyńska, 2013).

The aim of the current paper is to use a dynamic stochastic general equilibrium (DSGE) model to explain the differences in price stickiness and inflation persistence and to incorporate both types of heterogeneity within a general equilibrium model. The use of this type of model allows an analysis of the macroeconomic consequences of heterogeneity in price stickiness.

The model is designed using the mechanisms described by Benigno (2004) and Benigno and López-Salido (2006), who built a model of the economy using a single monetary authority while still allowing for sectoral heterogeneity in price setting. The model also describes a small open economy, here following Galí and Monacelli (2005) and Clarida et al. (2001). The model assumes a generic agent who is both the consumer and supplier of working hours for the purpose of production. The agent consumes a bundle of domestic and foreign goods but supplies labour to only one of the firms, which produces a single differentiated good in one of two sectors: $A$ and $B$. Sector $A$ represents the production of food and energy. The prices of these two components of the consumption basket have been reported to be the least sticky (Dhyne et al., 2006; for a similar study for Poland see Macias and Makarski, 2013). Sector $B$ consists of firms that produce services and goods other than food and energy. According to the analyses of individual prices, the prices of these products (especially services) are much more persistent than those of sector $A$. Because the production from sector $B$ fully covers the basket of the core inflation price index (the inflation net of food and energy), the model can be used to assess the role of core inflation in monetary policy.

The world economy consists of a continuum of economies, which share identical preferences, technologies, and market structures, including the division into two production sectors: $A$ and $B$. Because each economy is of measure zero, their policy decisions do not affect the rest of the world but are instead under the influence of the world economy as a whole. The model below describes one such economy where the rest of the world is treated as a single foreign country.

The model is then applied to Polish data using a Bayesian estimation. In a model comparison exercise, the Bayes factor is used to show the empirical advantages of a model that uses heterogeneous price-setting mechanisms in sectors $A$ and $B$ compared with a model that uses common price-setting rules across sectors. Finally, an impulse response function analysis is used to draw monetary policy conclusions.

The remainder of the paper is organized as follows. Section 2 covers the theoretical model, including details of consumer and producer decisions, both home and abroad. Sections 3 and 4 discuss the estimation procedure and the dataset, respectively. The main 
results of the Bayesian estimation and the policy analysis are presented in Section 5, which is followed by the final concluding section.

\section{Model}

\subsection{Households in the home country}

A continuum of agents, who obtain utility from consumption and disutility from labour at the time $t$, is indexed with $j$. The labour market in each sector is frictionless, but agents cannot change the sector for which they supply their labour. The agent $j$ at the time $t$ makes a decision regarding the level of consumption and labour, seeking to maximize the present value of the agent's utility in the infinite horizon:

$$
\max _{C_{j}, N_{j}} E_{t}\left\{\sum_{T=t}^{\infty} \beta^{T-t}\left[U\left(C_{j, T}, N_{j, T}\right)\right]\right\},
$$

where $E_{t}$ denotes rational expectations and $\beta$ is the discount factor. The utility function $U$ is separable between two factors $\left(C_{j}\right.$ - the agent's total consumption bundle and $N_{j}-$ the amount of labour supplied by an agent $j$ in a given sector) and is a constant relative risk aversion (CRRA) type of function:

$$
U\left(C_{j, t}, N_{j, t}\right)=e^{\varepsilon_{t}^{p}} \frac{C_{j, t}^{1-\sigma}}{1-\sigma}-\frac{N_{j, t}^{1+\varphi}}{1+\varphi},
$$

where $\sigma$ denotes the risk aversion and $\varphi$ is the inverse of the Frisch elasticity. The utility is also under the influence of the preference shock $\varepsilon_{t}^{p}$, which follows the AR(1) process: $\varepsilon_{t}^{p}=\rho_{p} \varepsilon_{t-1}^{p}+\zeta_{t}^{p} ; \zeta_{t}^{p} \sim$ iid $N\left(0, \varsigma_{p}^{2}\right)$. The consumption bundle that contains the goods produced in both sectors $A$ and $B$ is aggregated following Obstfeld and Rogoff (2000) by using the Cobb-Douglas function (the index $t$ is omitted in the following few steps because they concern the intratemporal decisions of a representative household):

$$
C_{j}=\frac{\left(C_{j}^{B}\right)^{n}\left(C_{j}^{A}\right)^{1-n}}{n^{n}(1-n)^{1-n}}, n \in[0,1] .
$$

Where $n$ is the share of goods produced in sector $B$ and $C_{j}^{B}$ and $C_{j}^{A}$ are consumption bundles containing the goods that are produced in the respective sectors. The elasticity of substitution between the goods from different sectors $\left(C_{j}^{B}\right.$ and $\left.C_{j}^{A}\right)$ is equal to one, meaning that the consumption of food and energy $(\operatorname{sector} A$ ) is fairly independent of the relative prices compared with the other consumer goods and services (sector $B$ ). One example of such a substitution would be switching from a private car (i.e., an energy consumption) to public transport (i.e., a service consumption) in the face of rising fuel prices. 
Indices $C_{j}^{B}$ and $C_{j}^{A}$ are aggregated using the constant elasticity of the substitution (CES) function, where $(1-m)$ is the steady-state share of home goods in each sector and $\eta$ is the elasticity of substitution between domestic $(H)$ and imported $(F)$ goods in both sectors. ${ }^{2}$ Consequently, $m$ is the degree of openness regarding these two different kinds of goods (this aggregation follows Galí and Monacelli, 2005):

$$
\begin{aligned}
& C_{j}^{A}=\left[(1-m)^{\frac{1}{\eta}}\left(C_{j}^{A, H}\right)^{\frac{\eta-1}{\eta}}+m^{\frac{1}{\eta}}\left(C_{j}^{A, F}\right)^{\frac{\eta-1}{\eta}}\right]^{\frac{\eta}{\eta-1}}, \\
& C_{j}^{B}=\left[(1-m)^{\frac{1}{\eta}}\left(C_{j}^{B, H}\right)^{\frac{\eta-1}{\eta}}+m^{\frac{1}{\eta}}\left(C_{j}^{B, F}\right)^{\frac{\eta-1}{\eta}}\right]^{\frac{\eta}{\eta-1}}, m \in[0,1] .
\end{aligned}
$$

Finally, at the lowest level of aggregation, $C_{j}^{A, H}, C_{j}^{A, F}, C_{j}^{B, H}$ and $C_{j}^{B, F}$, are defined as the DixitStiglitz indices of consumption (where each of the indices uses the same substitution parameter of $\epsilon>1$ ) across the continuum of differentiated goods produced in the respective sectors both home and abroad. Each sector in each country produces a continuum of differentiated goods represented by the unit interval:

$$
\begin{aligned}
& C_{j}^{A, F}=\left[\int_{0}^{1} C_{j}^{A}(f)^{\frac{\epsilon-1}{\epsilon}} d f\right]^{\frac{\epsilon}{\epsilon-1}}, \\
& C_{j}^{A, H}=\left[\int_{0}^{1} C_{j}^{A}(h)^{\frac{\epsilon-1}{\epsilon}} d h\right]^{\frac{\epsilon}{\epsilon-1}}, \\
& C_{j}^{B, F}=\left[\int_{0}^{1} C_{j}^{B}(f)^{\frac{\epsilon-1}{\epsilon}} d f\right]^{\frac{\epsilon}{\epsilon-1}}, \\
& C_{j}^{B, H}=\left[\int_{0}^{1} C_{j}^{B}(h)^{\frac{\epsilon-1}{\epsilon}} d h\right]^{\frac{\epsilon}{\epsilon-1}},
\end{aligned}
$$

where $C_{j}^{A}(h)$ and $C_{j}^{B}(h)$ are $j$ 's consumption of home-produced goods in sectors $A$ and $B$, respectively; $C_{j}^{A}(f)$ and $C_{j}^{B}(f)$ are $j$ 's consumption of foreign goods; $\epsilon$ (the elasticity of substitution across goods produced in a given sector in a given country) is assumed to be greater than 1; and the elasticity of substitution values between the consumption of goods from sectors $B$ and $A$ and from countries $H$ and $F$ are equal to 1 and $\eta$, respectively (see Equations 3-5).

2 The aggregation scheme with the substitution parameter $\eta=1$ collapses to become the CobbDouglas function, which is similar to function (3). 
Following the Dixit-Stiglitz approach, the overall price index $(P)$ is given by:

$$
P=\left(P^{B}\right)^{n}\left(P^{A}\right)^{1-n} .
$$

The price indices in the respective sectors $\left(P^{A}\right.$ and $\left.P^{B}\right)$ are aggregated from domestic $\left(P^{A, H}\right.$ and $\left.P^{B, H}\right)$ and foreign $\left(P^{A, F}\right.$ and $\left.P^{B, F}\right)$ price indices in the following way:

$$
\begin{aligned}
& P^{A}=\left[(1-m)\left(P^{A, H}\right)^{1-\eta}+m\left(P^{A, F}\right)^{1-\eta}\right]^{\frac{1}{1-\eta}}, \\
& P^{B}=\left[(1-m)\left(P^{B, H}\right)^{1-\eta}+m\left(P^{B, F}\right)^{1-\eta}\right]^{\frac{1}{1-\eta}} .
\end{aligned}
$$

In log terms, the total price level in the home economy is given by:

$$
p_{t}=n p_{t}^{B}+(1-n) p_{t}^{A}=n\left((1-m) p_{t}^{B, H}+m p_{t}^{B, F}\right)+(1-n)\left((1-m) p_{t}^{A, H}+p_{t}^{A, F}\right)=(1-m) p_{t}^{H}+m p_{t}^{F}
$$

Finally, the prices of each individual good are aggregated as follows:

$$
\begin{aligned}
& P^{A, F}=\left[\int_{0}^{1} P^{A}(f)^{1-\epsilon} d f\right]^{\frac{1}{1-\epsilon}}, \\
& P^{A, H}=\left[\int_{0}^{1} P^{A}(h)^{1-\epsilon} d h\right]^{\frac{1}{1-\epsilon}}, \\
& P^{B, F}=\left[\int_{0}^{1} P^{B}(f)^{1-\epsilon} d f\right]^{\frac{1}{1-\epsilon}}, \\
& P^{B, H}=\left[\int_{0}^{1} P^{B}(h)^{1-\epsilon} d h\right]^{\frac{1}{1-\epsilon}},
\end{aligned}
$$

where $P^{A, H}$ and $P^{B, H}$ are both the domestic price indices in their respective sectors and $P^{A, F}$ and $P^{B, F}$ are the price indices for imported goods, expressed in the domestic currency.

A household decides on the level of the total consumption $C_{j}$. Given this decision, it optimally allocates the expenditure among $C_{j}^{B}$ and $C_{j}^{A}$ (Equation 3), seeking to minimize the total expenditure $P C_{j}$. Next, given the decisions on $C_{j}^{B}$ and $C_{j}^{A}$, the agent allocates the expenditure between domestic and foreign goods $C_{j}^{B, H}$ and $C_{j}^{B, F}-$ or, in the other sector, $C_{j}^{A, H}$ and $C_{j}^{A, F}$ - seeking to minimize the total expenditures $P^{B} C_{j}^{B}$ and $P^{A} C_{j}^{A}$. Finally, given the latter decision, an agent decides on the consumption of each of the differentiated goods $C_{j}^{B}(h)$ and $C_{j}^{B}(f)$ - or, in the second sector, $C_{j}^{A}(h)$ and $C_{j}^{A}(f)$ - seeking to minimize expenditures on goods in each sector and in each country: $P^{B, H} C_{j}^{B, H}, P^{B, F} C_{j}^{B, F}, P^{A, H} C_{j}^{A, H}$, and $P^{A, F} C_{j}^{A, F}$. 
The timing of the consumer's decision can be summarized as follows. The consumer (i) decides how much to consume and then (ii) decides what kind of good ( $A$ or $B$ ) to consume and in what amount; the consumer then (iii) chooses the proportions of the home and foreign bundle and finally (iv) decides on each individual good. These decisions are all conditional on the prices and elasticity of substitution of the respective choices. The aggregation scheme is summarized in Figure 1.

Figure 1: Structure of a Representative Household's Consumption Bundle

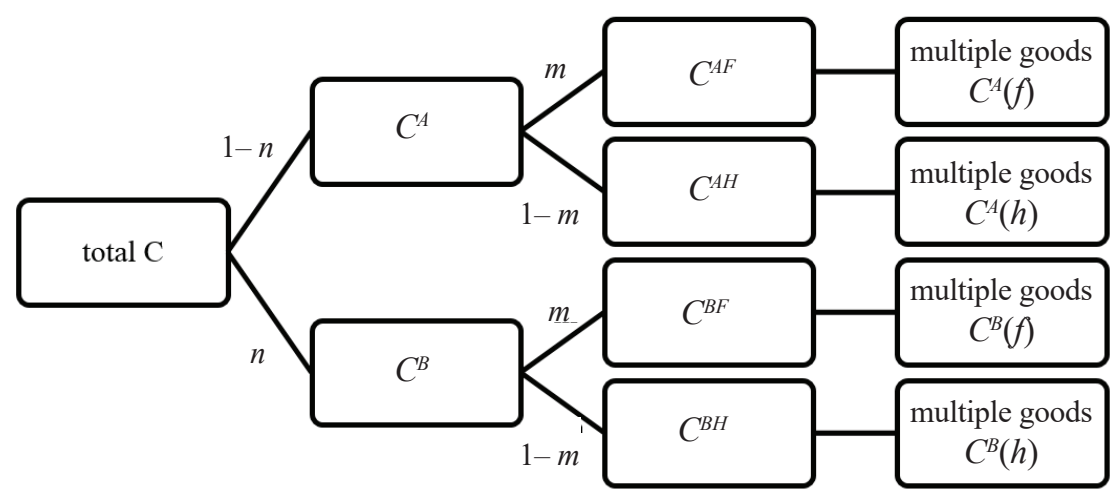

Source: Own assumptions.

Similar to the models of Benigno (2004), Obstfeld and Rogoff (2000), and many other open DSGE models that adopt the law of one price, the model derived here assumes no transaction costs or any other barriers in purchasing the goods produced in sectors $A$ and $B$. Also, the law of one price is assumed explicitly, so there are no barriers in trading the goods produced in a foreign country. Consequently, each good has one price (with respect to a given currency) that applies to all of the transactions; this allows us to omit the index $j$ from the consumption-based price indices (Benigno, 2004).

Under the Dixit-Stiglitz aggregation (see Equations 6-9 and 13-16), the representative household's demand for each of the domestic and foreign-produced goods in sectors $A$ and $B$ are provided by the following equations:

$$
\begin{gathered}
C_{j}^{A}(f)=\left[\frac{P^{A}(f)}{P^{A, F}}\right]^{-\epsilon} C_{j}^{A, F}, \\
C_{j}^{A}(h)=\left[\frac{P^{A}(h)}{P^{A, H}}\right]^{-\epsilon} C_{j}^{A, H},
\end{gathered}
$$




$$
\begin{aligned}
& C_{j}^{B}(f)=\left[\frac{P^{B}(f)}{P^{B, F}}\right]^{-\epsilon} C_{j}^{B, F}, \\
& C_{j}^{B}(h)=\left[\frac{P^{B}(h)}{P^{B, H}}\right]^{-\epsilon} C_{j}^{B, H} .
\end{aligned}
$$

The next level of aggregation (see Equations 3-5) implies that the demand for each sector's consumption bundle (the composite consumption index) is given by:

$$
\begin{aligned}
& C_{j}^{B, H}=(1-m)\left(\frac{P^{B, H}}{P^{B}}\right)^{-\eta} C_{j}^{B}, \\
& C_{j}^{B, F}=m\left(\frac{P^{B, F}}{P^{B}}\right)^{-\eta} C_{j}^{B}, \\
& C_{j}^{A, H}=(1-m)\left(\frac{P^{A, H}}{P^{A}}\right)^{-\eta} C_{j}^{A}, \\
& C_{j}^{A, F}=m\left(\frac{P^{A, F}}{P^{A}}\right)^{-\eta} C_{j}^{A}, \\
& C_{j}^{B}=n\left(\frac{P^{B}}{P}\right)^{-1} C_{j}, \\
& C_{j}^{A}=(1-n)\left(\frac{P^{A}}{P}\right)^{-1} C_{j} .
\end{aligned}
$$

Finally, the demand equations at each level of aggregation can be combined with the definition of the total consumption in the economy: $C=\int_{0}^{1} C_{j} d j$. This calculation yields the demand equation for each individual good with respect to the total level of consumption:

$$
\begin{aligned}
& C_{j}^{A}(h)=(1-m)(1-n)\left[\frac{P^{A}(h)}{P^{A, H}}\right]^{-\epsilon}\left(\frac{P^{A, H}}{P^{A}}\right)^{-\eta}\left(\frac{P^{A}}{P}\right)^{-1} C, \\
& C_{j}^{B}(h)=(1-m) n\left[\frac{P^{B}(h)}{P^{B, H}}\right]^{-\epsilon}\left(\frac{P^{B, H}}{P^{B}}\right)^{-\eta}\left(\frac{P^{B}}{P}\right)^{-1} C .
\end{aligned}
$$


It is useful to define the relative price between sectors as $S \equiv \frac{P^{A}}{P^{B}}$. The relative prices between domestic and foreign products will be discussed when describing the foreign country (see Section 2.2).

The model assumes complete asset markets, hence allowing consumers to borrow against their future income; the budget constraints for decisions regarding the level of consumption and labour at the time $t$ (Equation 1) are thus given by the following:

$$
P_{t} C_{t}+R_{t} B_{t}=B_{t-1}+W_{t} N_{t}+I_{t},
$$

where $B_{t}$ represents one-period bonds purchased at the time $t$ for the price $R_{t}$ and sold at the time $t+1$ for the bonds' nominal value; $W_{t} N_{t}$ is the agent's income from labour, where $W_{t}$ is the nominal wage in the sector for which an agent supplies labour $N_{t}$; and $I_{t}$ is a lump-sum component of income, which includes the profits from firms that are transferred after the production decision has been made (see Section 2.4). The total consumption expenditures $\left(P_{t} C_{t}\right)$ contain all the goods aggregated, as described above, so the budget constraint can be collapsed to a simple one-sector closed-economy form (see Galí, 2008). This situation allows viewing the optimization problem as a decision made by a representative agent because neither the objective function nor the budget constraint contain sector-specific variables. This budget constraint is supplemented with a solvency condition: $\lim _{T \rightarrow \infty} E_{t}\left\{B_{T}\right\} \geq 0$ for all $t$.

The maximization of utility in the infinite horizon can be represented as a recursive structure under the assumption of rational expectations. Using the Bellman method, the infinite horizon optimization problem can be approximated using a two-period choice (Wickens, 2008, p. 434). Solving expression (1) subject to Equation 29 yields the following first-order conditions:

$$
\begin{aligned}
& \frac{W_{t}}{P_{t}}=e^{-\varepsilon_{t}^{p}} C_{t}^{\sigma} N_{t}^{\varphi}, \\
& R_{t}=\beta E_{t}\left\{e^{\varepsilon_{t}^{p}}\left(\frac{C_{t+1}}{C_{t}}\right)^{-\sigma} \frac{P_{t}}{P_{t+1}}\right\} .
\end{aligned}
$$

Taking the log of Equation 31, the aggregate demand curve is given by:

$$
c_{t}=E_{t}\left\{c_{t+1}\right\}-\frac{1}{\sigma}\left(i_{t}-E_{t}\left\{\pi_{t+1}\right\}-\varrho+\varepsilon_{t}^{p}\right),
$$

where $c_{t}$ is the $\log$ of consumption; $i_{t}=\ln \left(R_{t}\right)$ is the nominal interest rate; $\varrho=\ln \beta$ is the discount rate; and $\pi_{t+1}=\ln \left(P_{t+1} / P_{t}\right)$ is the total consumer inflation rate. Given Equations 10 and 12a, the total inflation rate can be stated as the weighted average 
of the inflation rates in sectors $A$ and $B\left(\pi_{t}^{A}\right.$ and $\left.\pi_{t}^{B}\right)$ and the inflation rates of home $\left(\pi_{t}^{A, H}\right.$ and $\left.\pi_{t}^{B, H}\right)$ and foreign $\left(\pi_{t}^{A, F}\right.$ and $\left.\pi_{t}^{B, F}\right)$ consumption subaggregates:

$$
\begin{aligned}
& \pi_{t}=n \pi_{t}^{B}+(1-n) \pi_{t}^{A}, \\
& \pi_{t}=n\left[(1-m) \pi_{t}^{B, H}+m \pi_{t}^{B, F}\right]+(1-n)\left[(1-m) \pi_{t}^{A, H}+m \pi_{t}^{A, F}\right] .
\end{aligned}
$$

\subsection{The foreign country}

The rest of the world shares identical preferences and a similar economy structure, with the same demand elasticities for goods from sectors $A$ and $B$. All of the variables in the foreign country (i.e., the rest of the world) are denoted with an asterisk (*). Following Galí and Monacelli (2005), the model assumes the law of one price across home and foreign economies:

$$
\begin{aligned}
& P_{t}^{A, F}=E X_{t} P_{t}^{A^{*}}, \\
& P_{t}^{B, F}=E X_{t} P_{t}^{B^{*}},
\end{aligned}
$$

where $P_{t}^{A^{*}}\left(P_{t}^{B^{*}}\right)$ is the foreign currency price of foreign-produced goods from sectors $A(B)$ and $E X_{t}$ is the nominal exchange rate. The purchasing power parity (PPP) states that the general price levels in the home and foreign country are equal:

$$
P_{t}=E X_{t} P_{t}^{*}
$$

where $P_{t}$ is the consumer price index (CPI) in the home country and $P_{t}^{*}$ is the CPI in a foreign country. For the rest of the world, the distinction between the general price level (i.e., CPI) and the price level of the foreign-produced goods can be ignored because the foreign economy (i.e., the rest of the world) is so large relative to the home economy that the prices of home-produced goods $\left(P_{t}^{A, H}\right.$ and $\left.P_{t}^{B, H}\right)$ have a negligible impact on the CPI of the rest of the world. ${ }^{3}$

The terms of trade are defined as:

$$
\operatorname{ToT}_{t}=\frac{P_{t}^{F}}{P_{t}^{H}}=\frac{E X_{t} P_{t}^{*}}{P_{t}^{H}} \text {. }
$$

The real exchange rate $\left(Q_{t}\right)$ is the price of foreign-produced goods in domestic currency relative to the home economy's CPI:

3 This is a standard assumption in small open economy (SOE) models (Galí and Monacelli, 2005). 


$$
Q_{t}=\frac{E X_{t} P_{t}^{*}}{P_{t}}=\frac{P_{t}^{H}}{P_{t}} T_{o} T_{t} .
$$

The relationship between the real exchange rate and the terms of trade in log terms is shown using the definition of the terms of trade (Equation 38) and the aggregation of the total price level (Equation 12a):

$$
q_{t}=(1-m) \text { tot }_{t} .
$$

The assumption of international risk sharing (Walsh, 2010, p. 434) leads to the following log-linear representation of the relationship of domestic and foreign total consumption:

$$
c_{t}=c_{t}^{*}+\left(\frac{1-m}{\rho}\right) \text { tot }_{t}=c_{t}^{*}+\left(\frac{1}{\rho}\right) q_{t},
$$

where $(1-m)$ is the share of the home-produced goods in the consumption basket. The Euler condition for foreign households implies the following:

$$
y_{t}^{*}=E_{t}\left\{y_{t+1}^{*}\right\}-\frac{1}{\sigma}\left(i_{t}^{*}-E_{t}\left\{\pi_{t+1}^{*}\right\}-\varrho^{*}+\varepsilon_{t}^{p^{*}}\right) .
$$

Note that because of the small size of the economy compared with the rest of the world, there is a market-clearing assumption that states that the total foreign production equals the total foreign consumption: $y_{t}^{*}=c_{t}^{*}$.

\subsection{Market clearing and equilibrium}

The market-clearing condition states that the total production in the economy $\left(Y_{t}\right)$ equals the economy's consumption, both home and abroad:

$$
Y_{t}=(1-m)\left(\frac{P_{t}^{H}}{P_{t}}\right)^{-1} C_{t}+m\left(\frac{P_{t}^{H}}{E X_{t} P_{t}^{*}}\right)^{-1} Y_{t}^{*} .
$$

After a few transformations (see Walsh, 2010, pp. 430-439) and a log linearization around the steady state, ${ }^{4}$ the equilibrium condition is as follows:

$$
y_{t}=c_{t}+\left(\frac{m \cdot v}{\sigma}\right) \text { tot }_{t}
$$

where $v=\eta \sigma+(\eta \sigma-1)(1-m)$. Using Equation 41 and market clearing in the foreign country, the equilibrium condition can be written as:

$4 \quad$ In the steady state, $Q_{t}=1$. 


$$
y_{t}=y_{t}^{*}+\left(\frac{1}{\sigma^{m}}\right) \text { tot }_{t},
$$
where $\sigma^{m}=\frac{\sigma}{1-m(1-v)}$. Using Equation 43, the Euler condition (Equation 32) can be written
as:

$$
y_{t}=E_{t}\left\{y_{t+1}\right\}-\frac{1}{\sigma}\left(i_{t}-E_{t}\left\{\pi_{t+1}\right\}-\varrho+\varepsilon_{t}^{p}\right)-\left(\frac{m \cdot v}{\sigma}\right)\left(E_{t} \Delta t o t_{t+1}\right) .
$$

Next, using the definition of the CPI (Equation 12a) and the log-linear terms of the trade formula (Equation 38), one can determine the economy's output gap as a function of home inflation, interest rate, and the terms of trade; this representation directly follows Galí and Monacelli (2005, p. 717):

$$
y_{t}=E_{t}\left\{y_{t+1}\right\}-\frac{1}{\sigma}\left(i_{t}-E_{t}\left\{\pi_{t+1}^{H}\right\}-\varrho+\varepsilon_{t}^{p}\right)-\frac{m(v-1)}{\sigma}\left(E_{t} \Delta t o t_{t+1}\right) .
$$

Finally, after rearranging the terms, a dynamic IS equation for a small, open, two-sector economy is derived as follows:

$$
\hat{y}_{t}=E_{t}\left\{\hat{y}_{t+1}\right\}-\frac{1}{\sigma}\left(i_{t}-E_{t}\left\{\pi_{t+1}^{H}\right\}+\varepsilon_{t}^{p}\right)-\frac{m(v-1)}{\sigma}\left(E_{t} \Delta t_{t+1}\right)
$$

where $\hat{y}_{t}=y_{t}-\tilde{y}_{t}$ denotes the output gap, that is, the deviation of the output from the flexible-price steady state $\left(\tilde{y}_{i}\right)$.

\subsection{The firms}

The firms that supply goods to the market operate in two sectors, both of which are environments of monopolistic competition. The sectors are designed in a similar manner as in Benigno and López-Salido (2006), who built a model of a currency area of two regions, each with a different price-setting mechanism. Essentially, their model of an economy with sectoral price-setting heterogeneity assumes that the countries in a currency union differ in price stickiness and inflation persistence. In one country, the prices are set in a fully forward-looking manner (the standard Calvo-Yun model), whereas in the other country, the prices are set using a model developed by Galí and Gertler (1999), which has a backward-looking component. The two countries form one economy that has a single monetary authority and a homogenous production process.

In the current paper, this construction is transformed into a case of one country that consists of sectors with different price-setting mechanisms. The main difference is the presence of intrinsic inflation persistence (i.e., a backward-looking fraction of firms) in both sectors. 
In a given sector $(A$ and $B)$, the producers set their prices according to the standard model (Galí and Gertler, 1999), where for any given period, forward-looking firms are allowed to change their price with a constant probability: $\left(1-\theta^{A}\right)$ and $\left(1-\theta^{B}\right)$. The price is set by taking into account the expected discounted value of a firm's profits and the probability of encountering price rigidity in the future. Apart from forward-looking agents, a fraction of firms $\left(\omega^{A}\right.$ and $\left.\omega^{B}\right)$ also set their prices in a backward-looking manner - that is, by indexing their prices with past inflation rates. This distinction creates substantial differences in the inflation dynamics, as shown below.

In the home economy, a continuum of firms is indexed with $j \in[0,1]$. The firms operate in two sectors indexed with $i$ : sector $i=B$, if $j \in[0, n)$ and $[n, 1]$ and sector $i=A$, if $j \in[n, 1]$. The firms' products are $Y^{B}(h)$ and $Y^{A}(h)$, respectively. Each firm in a given sector uses the same kind of production function:

$$
\begin{aligned}
& Y_{t}^{A}(h)=Z_{t}^{A} \cdot N_{t}^{A}(h) \\
& Y_{t}^{B}(h)=Z_{t}^{B} \cdot N_{t}^{B}(h),
\end{aligned}
$$

where $Z_{t}^{A}$ and $Z_{t}^{B}$ are the sector-specific technologies; in $\log$ terms: $Z_{t}^{A} \equiv \ln \left(Z_{t}^{A}\right)$ and $Z_{t}^{B} \equiv \ln \left(Z_{t}^{B}\right)$. Both are defined as stochastic processes driven only by sectorspecific technology shocks: $z_{t}^{A}=\varepsilon_{t}^{A}$ and $z_{t}^{B}=\varepsilon_{t}^{B}$. The technology shocks are defined as $\varepsilon_{t}^{A} \sim$ iid $N\left(0, \varsigma_{A}^{2}\right)$ and $\varepsilon_{t}^{B} \sim$ iid $N\left(0, \varsigma_{B}^{2}\right)$. The assumption of no persistence in the technology shocks is very strong and can be empirically discarded at the microeconomic level. However, this type of construction has an advantage from the point of view of the estimation procedure. The rationale behind the assumptions about all of the shocks and the robustness check concerning the persistent technology shocks are described in Section 3.

Additionally, $N_{t}$ is the amount of labour used in the production process. Note also that the production function assumes constant returns to scale.

The firms operate under monopolistic competition and hence are allowed to set their own prices under two constraints: price stickiness and demand functions (Equations 18 and 20, respectively). The optimal price is set in a profit-maximizing way and takes into account the infinite horizon and the probability of keeping the same price in the following periods. In sector $A$, the national producers choose their optimal price maximization, as in the following expression (see Benigno and López-Salido, 2006, p. 590):

$$
\max E_{t}\left\{\sum_{k=0}^{\infty}\left(\theta^{A}\right)^{k} \cdot \Xi_{t, t+k}\left[P_{t}^{\#, A}(h) \cdot Y_{t, t+k}^{A}(h)-W_{t+k}^{A}(h) \cdot \frac{Y_{t, t+k}^{A}(h)}{Z_{t+k}^{A}}\right]\right\},
$$

where $P_{t}^{\#, A}(h)$ is the optimal price for a representative firm in sector $A ; Y_{t, t+k}(h)$ is the total demand for a firm's product at the time $t+k$, conditional on the fact that the price $P_{t}^{\#, A}(h)$ still applies; and $W_{t+k}^{A}(h)$ denotes the nominal wage for the labour used by the firm $j$. 
In addition, $\Xi_{t, t+k}$ is the stochastic discount factor used to evaluate future nominal income in units of present nominal income, as follows:

$$
\Xi_{t, t+k}=\beta^{k} \frac{U_{C}\left(C_{t+k}\right)}{U_{C}\left(C_{t}\right)} \frac{P_{t}}{P_{t+k}} .
$$

The optimal price in Equation 48 lacks the index $j$ because every firm operating in sector $A$ faces the same cost function, the same probability $\theta^{A}$, and the same demand function. Therefore, under rational expectations, each firm comes up with the same optimal price.

After plugging in the demand function in place of $Y_{t, t+k}^{A}(h)$, the first-order condition for finding the extremum of expression 48 can be written as:

$$
P_{t}^{\#, A}(h)=\frac{\epsilon}{\epsilon-1} \frac{E_{t}\left\{\sum_{k=0}^{\infty}\left(\theta^{A}\right)^{k} \cdot \Xi_{t, t+k} \cdot M C N_{t, t+k}^{A}(h) \cdot Y_{t, t+k}^{A}(h)\right\}}{E_{t}\left\{\sum_{k=0}^{\infty}\left(\theta^{A}\right)^{k} \cdot \Xi_{t, t+k} \cdot Y_{t, t+k}^{A}(h)\right\}},
$$

where $\operatorname{MCN}_{t, t+k}^{A}(h)$ is the nominal marginal cost at the time $t+k$, given that the optimal price from the period $t$ still holds. Rearranging the terms and substituting the stochastic discount factor yields the following:

$$
E_{t}\left\{\sum_{k=0}^{\infty}\left(\theta^{A} \beta\right)^{k} U_{C}\left(C_{t+k}\right) Y_{t, t+k}^{A}(h) \frac{P_{t+k}^{A, H}}{P_{t+k}^{H}}\left[\frac{P_{t}^{\#, A}(h)}{P_{t}^{A, H}} \frac{P_{t}^{A, H}}{P_{t+k}^{A, H}}-\frac{\epsilon}{\epsilon-1} M C R_{t, t+k}^{A}(h)\right]\right\}=0,
$$

where $M C R_{t, t+k}^{A}(h)=M C N_{t, t+k}^{A}(h) / P_{t+k}^{A, H}$ is the real marginal cost at the time $t+k$, given that the optimal price from the period $t$ still holds.

The log-linear approximation of the first-order condition around the zero inflation steady state (where $\frac{P_{t}^{\#, A}(h)}{P_{t}^{A, H}}=1$ and $\frac{P_{t+k}^{A, H}}{P_{t}^{A, H}}=1$ ) produces the following result:

$$
E_{t}\left\{\sum_{k=0}^{\infty}\left(\theta^{A} \beta\right)^{k}\left[\widehat{p_{t}^{\#, A}}(h)-\widehat{m c r_{t, t+k}^{A}}(h)-\sum_{\tau=1}^{k} \pi_{t+\tau}^{A, H}\right]\right\}=0
$$

where $\pi_{t}^{A, H}=\ln \frac{P_{t}^{A, H}}{P_{t-1}^{A, H}}, \widehat{p_{t}^{\#, A}}(h)=\ln \frac{P_{t}^{\#, A}(h)}{P_{t}^{A, H}}$ and $\widehat{m c r}_{t, t+k}^{A}(h)=\ln \frac{M C R_{t, t+k}^{A}(h)}{M C}$ denotes the $\log$ deviation of the real marginal cost in sector $A$ from its steady state. To reach this approximation, note that under the isoelastic demand function with a price elasticity $\epsilon$, the optimal price gross markup is given by $\mathrm{M}=\frac{\epsilon}{\epsilon-1}$, and the real marginal cost in the steady state $(M C)$ is assumed to equal the value's reciprocal (see Galí, 2008).

Equilibrium on the labour market implies that the firms hire until real wages equal the marginal product of labour $\left(M P L^{A}\right)$. This situation leads to the following derivation of the nominal marginal cost faced by the firms in sector $A$ at the moment of optimization: 


$$
M C N_{t, t+k}^{A}(h)=\frac{W_{t+k}^{A}(h)}{M P L_{t, t+k}^{A}}=\frac{W_{t+k}^{A}(h)}{Z_{t+k}^{A}} .
$$

Note that because the production function assumes constant returns to scale, the marginal cost is independent of the level of production and is common across firms (Galí, 2008, p. 47). This assumption allows for the establishment of the optimal price in sector $A$ as a function of the average marginal cost and the sectoral inflation rate in the home country:

$$
\widehat{p_{t}^{\#, A}}(h)=\left(1-\theta^{A} \beta\right) \sum_{k=0}^{\infty}\left(\theta^{A} \beta\right)^{k}\left[\widehat{\operatorname{mcr}}_{t+k}^{A}+\sum_{\tau=1}^{k} \pi_{t+\tau}^{A, H}\right] \text {. }
$$

The optimal price is the same in every firm, but not all the firms can or want to decide to change their prices according to this optimum. As in Galí and Gertler (1999), there are two types of firms: those that optimize $\left(1-\omega^{4}\right)$ and those that follow a rule of thumb $\left(\omega^{4}\right)$. All of the firms may change the price only if they do not encounter a barrier. The probability that a price rigidity will occur is equal to $\theta^{4}$ and is independent of the time when the price is fixed. During each period, an optimizing firm may thus: change its price to the optimal level with the probability of $1-\theta^{4}$, or keep the price unchanged with the probability of $\theta^{4}$.

The firms following the rule of thumb, in contrast, set their prices by indexing them using the sectoral inflation rate $\left(\pi_{t-1}^{A, H}\right)$. This mechanism represents those firms that do not engage in complicated cost-benefit analyses of their price-level policies. Instead, they mimic the behaviour of other companies. This type of pricing mechanism results in the inflation rate in sector $A$, as given by the following:

$$
\pi_{t}^{A, H}=\left(1-\theta^{A}\right)\left(1-\omega^{A}\right)\left[\widehat{p_{t}^{\#, A}}(h)-p_{t-1}^{A, H}\right]+\omega^{A} \pi_{t-1}^{A, H} .
$$

Combining Equation 55 with Equation 54 provides the new Keynesian Phillips curve explaining inflation in sector $A$ in the home economy:

$$
\pi_{t}^{A, H}=\lambda^{A} \widehat{m c r}_{t}^{A}+\gamma_{1}^{A} E_{t}\left\{\pi_{t+1}^{A, H}\right\}+\gamma_{2}^{A} \pi_{t-1}^{A, H},
$$

where the combinations of the underlying microeconomic parameters are the follo-wing:

$$
\lambda^{A}=\frac{\left(1-\theta^{A} \beta\right)\left(1-\theta^{A}\right)\left(1-\omega^{A}\right)}{\phi^{A}}, \gamma_{1}^{A}=\frac{\theta^{A} \beta}{\phi^{A}}, \gamma_{2}^{A}=\frac{\omega^{A}}{\phi^{A}} \text { and } \phi^{A}=\theta^{A}+\omega^{A}\left(1-\theta^{A}(1-\beta)\right) .
$$

Sector $B$ in the home economy is the production of consumption goods other than food and energy. The derivation of the new Keynesian Phillips curve in sector $B$ is very similar to that in sector $A$. A producer who operates in sector $B$ finds the optimal price $P_{t}^{\#, B}(h)$ by means of the following optimization, which is equivalent to expression 48 : 


$$
\max _{P_{t}^{t, A}(h)} E_{t}\left\{\sum_{k=0}^{\infty}\left(\theta^{B}\right)^{k} \cdot \Xi_{t, t+k}\left[P_{t}^{\#, B}(h) \cdot Y_{t, t+k}^{B}(h)-W_{t+k}^{B}(h) \cdot \frac{Y_{t, t+k}^{B}(h)}{Z_{t+k}^{B}}\right]\right\} .
$$

To determine the optimal price in sector $B$, the same steps as in Equations 48-54 are used. The only difference at this point is the different parameters $\left(\theta^{B}\right.$ and $\left.\omega^{B}\right)$, which reflects the fact that the price-setting mechanisms for food and energy producers have different levels of price rigidity than producers of other goods and services. Therefore, the prices in sector $B$ follow the law of motion given by the following:

$$
\pi_{t}^{B, H}=\left(1-\theta^{B}\right)\left(1-\omega^{B}\right)\left(\widehat{p_{t}^{\#, B}}(h)-p_{t-1}^{B, H}\right)+\omega^{B} \pi_{t-1}^{B, H},
$$

where $\pi_{t}^{B, H}$ is the inflation rate in the sector that produces services and goods other than food and energy, $\widehat{p_{t}^{\#, B}}(h)$ is defined as $\widehat{p_{t}^{\#, B}}(h)=\ln \left(\frac{P_{t}^{\#, B}(h)}{P_{t}^{B, H}}\right)$, and $p_{t-1}^{B, H}=\ln P_{t-1}^{B, H}$.

The combination of the outcome of the optimization problem (with a log-linearized first-order condition) is provided by the following:

$$
\widehat{p_{t}^{\#, B}}(h)=\left(1-\theta^{B} \beta\right) \sum_{k=0}^{\infty}\left(\theta^{B} \beta\right)^{k}\left[\widehat{m c r}_{t+k}^{B}+\sum_{\tau=1}^{k} \pi_{t+\tau}^{B, H}\right] \text {. }
$$

This is equivalent to the optimal price in sector $A$, which is given by (54). Respectively, $\widehat{m c r}_{t}^{B}$ denotes the log deviation of the marginal cost in sector $B$ from the steady state.

In addition, the law of motion for prices (Equation 58) yields the new Keynesian Phillips curve for home inflation in sector $B$ :

$$
\pi_{t}^{B, H}=\lambda^{B} \widehat{m c r}_{t}^{B}+\gamma_{1}^{B} E_{t}\left\{\pi_{t+1}^{B, H}\right\}+\gamma_{2}^{B} \pi_{t-1}^{B, H},
$$

where $\lambda^{B}=\frac{\left(1-\theta^{B} \beta\right)\left(1-\theta^{B}\right)\left(1-\omega^{B}\right)}{\phi^{B}}, \gamma_{1}^{B}=\frac{\theta^{B} \beta}{\phi^{B}}, \gamma_{2}^{B}=\frac{\omega^{B}}{\phi^{B}}$, and $\phi^{B}=\theta^{B}+\omega^{B}\left(1-\theta^{B}(1-\beta)\right)$.

It should be noted that inflation in sector $B$ is measured by the CPI excluding food and energy prices. Therefore, Equation 60 represents the Phillips curve for the home component of the core inflation. In order to link the sectoral Phillips curves with the IS equation (Equation 46), the inflation rates need to be expressed as a function of the output gap rather than the marginal cost. Therefore, the marginal cost in real terms $\left(M C R_{t}^{A}=\frac{M C N_{t}^{A}}{P_{t}^{A, H}}\right)$ is used to combine the labour-demand condition with the labor-supply condition $M C N_{t}^{A}=\frac{W_{t}}{M P L_{t}}$, such that real wages equal the marginal rate of substitution between consumption and labour $\frac{W_{t}}{P_{t}}=\frac{-U_{N}\left(C_{t}, N_{t}\right)}{U_{C}\left(C_{t}, N_{t}\right)}$. The equality on the labour market under the linear-production function then yields: 


$$
\begin{gathered}
M C R_{t}^{A}=\frac{\left(N_{t}^{A}\right)^{\varphi}}{C_{t}^{-\sigma} Z_{t}^{A}} \frac{P_{t}}{P_{t}^{A, H}}=\frac{\left(Y_{t}^{A, H}\right)^{\varphi}}{C_{t}^{-\sigma}\left(Z_{t}^{A}\right)^{(1+\varphi)}} \frac{P_{t}}{P_{t}^{H}} \frac{P_{t}^{H}}{P_{t}^{A, H}}=\frac{\left(Y_{t}^{A, H}\right)^{\varphi}}{C_{t}^{-\sigma}\left(Z_{t}^{A}\right)^{(1+\varphi)}} \frac{P_{t}}{P_{t}^{H}} \frac{P_{t}^{H}}{P_{t}^{A, H}}, \\
M C R_{t}^{B}=\frac{\left(N_{t}^{B}\right)^{\varphi}}{C_{t}^{-\sigma} Z_{t}^{B}} \frac{P_{t}}{P_{t}^{B, H}}=\frac{\left(Y_{t}^{B, H}\right)^{\varphi}}{C_{t}^{-\sigma}\left(Z_{t}^{B}\right)^{(1+\varphi)}} \frac{P_{t}}{P_{t}^{H}} \frac{P_{t}^{H}}{P_{t}^{B, H}}=\frac{\left(Y_{t}^{B, H}\right)^{\varphi}}{C_{t}^{-\sigma}\left(Z_{t}^{B}\right)^{(1+\varphi)}} \frac{P_{t}}{P_{t}^{H}} \frac{P_{t}^{H}}{P_{t}^{B, H}} .
\end{gathered}
$$

The definition of the terms of trade allows us to write down the following relations: $p_{t}^{A}=p_{t}^{A, H}+m t o t_{t}^{A}$ and $p_{t}^{B}=p_{t}^{B, H}+m t o t_{t}^{B}$ (see Walsh, 2010, p. 432). Using also $S \equiv \frac{P^{A}}{P^{B}}$ as the relative price between sectors, the log-linear version of the above equations yields, respectively:

$$
\begin{aligned}
& m c r_{t}^{A}=\varphi y_{t}^{A, H}+\sigma \mathrm{c}_{\mathrm{t}}-(1+\varphi) \mathrm{z}_{\mathrm{t}}^{A}+m t o t_{t}^{A}-n s_{t}, \\
& m c r_{t}^{B}=\varphi y_{t}^{B, H}+\sigma \mathrm{c}_{\mathrm{t}}-(1+\varphi) \mathrm{z}_{\mathrm{t}}^{B}+m t o t_{t}^{B}+(1-n) s_{t} .
\end{aligned}
$$

Taking into account the demand for sectoral production (Equations 21-26), the relationship between sectoral and total production can be established:

$$
\begin{aligned}
& Y_{t}^{A, H}=(1-m)\left(\frac{P_{t}^{A, H}}{P_{t}^{A}}\right)^{-\eta}(1-n)\left(\frac{P_{t}^{A}}{P_{t}}\right)^{-1} Y_{t}=(1-m)(1-n) Y_{t} \cdot\left(\frac{P_{t}^{A, H}}{P_{t}^{A}}\right)^{-\eta} S_{t}^{-n}, \\
& Y_{t}^{B, H}=(1-m)\left(\frac{P_{t}^{B, H}}{P_{t}^{B}}\right)^{-\eta} n\left(\frac{P_{t}^{B}}{P_{t}}\right)^{-1} Y_{t}=(1-m) n Y_{t} \cdot\left(\frac{P_{t}^{B, H}}{P_{t}^{B}}\right)^{-\eta} S_{t}^{(1-n)} .
\end{aligned}
$$

With the market-clearing condition from Equation 43 yielding $y_{t}=c_{t}+\left(\frac{m \cdot v}{\sigma^{m}}\right) t_{t} t_{t}$ and with the log-linear approximation of the relative prices of domestic and foreign-produced goods around the steady state satisfying strong PPP $\left(p_{t}-p_{t}^{H} \approx m t o t_{t}\right)$, the following can be concluded:

$$
\begin{aligned}
& m c r_{t}^{A}=\varphi((1-m)+(1-n))+\left(\varphi+\sigma^{m}\right) y_{t}-(1+\varphi) \mathrm{z}_{\mathrm{t}}^{A}-n(\varphi+1) s_{t}+(\varphi \eta+1-m v) \text { tot }_{。} \\
& m c r_{t}^{B}=\varphi(1-m+n)+\left(\varphi+\sigma^{m}\right) y_{t}-(1+\varphi) \mathrm{z}_{\mathrm{t}}^{B}+(1-n)(\varphi+1) s_{t}+(\varphi \eta+1-m v) \text { tot }_{t} .
\end{aligned}
$$

Following Galí and Monacelli (2005, p. 718), one can derive the deviations of Equations 61 and 62 from the flexible-price steady state, which constitutes the relation between the sectoral marginal cost and the output gap. Note that in the steady state under flexible prices, the marginal cost is constant and equal to $M C R^{A}=M C R^{B}=\frac{1}{\mathrm{M}}=\frac{\epsilon-1}{\epsilon}$ or, 
in $\log$ terms, $m c r^{A}=m c r^{B}=-\ln (\mathrm{M})=-\mu$. The natural level of output $\left(\tilde{y}_{t}\right)$ is a function of the technologies in both sectors and in terms of trade, as shown by the following (see Benigno and López-Salido, 2006, p. 612):

$$
\begin{aligned}
& \widehat{m c r}_{t}^{A}=\left(\varphi+\sigma^{m}\right) \hat{y}_{t}-n(\varphi+1) \hat{s}_{t}, \\
& \widehat{m c r}_{t}^{B}=\left(\varphi+\sigma^{m}\right) \hat{y}_{t}+(1-n)(\varphi+1) \hat{s}_{t},
\end{aligned}
$$

where the hats denote the log deviations from the flexible-price steady state: $\hat{y}_{t}=y_{t}-\tilde{y}_{t}$, $\hat{s}_{t}=s_{t}-\tilde{s}_{t}$.

Plugging Equations 63 and 64 into Equations 56 and 60 yields the sectoral Phillips curves with respect to the output gap:

$$
\begin{aligned}
& \pi_{t}^{A, H}=\lambda^{A}(\varphi+\sigma) \hat{y}_{t}-n \lambda^{A}(\varphi+1) \hat{s}_{t}+\gamma_{1}^{A} E_{t}\left\{\pi_{t+1}^{A, H}\right\}+\gamma_{2}^{A} \pi_{t-1}^{A, H}+\varepsilon_{t}^{A}, \\
& \pi_{t}^{B, H}=\lambda^{B}(\varphi+\sigma) \hat{y}_{t}+(1-n) \lambda^{B}(\varphi+1) \hat{s}_{t}+\gamma_{1}^{B} E_{t}\left\{\pi_{t+1}^{B, H}\right\}+\gamma_{2}^{B} \pi_{t-1}^{B, H}+\varepsilon_{t}^{B} .
\end{aligned}
$$

\subsection{The law of motion of the remaining variables}

The microeconomic assumptions described in Sections 2.1-2.3 lead to the formulation of the relationships between the main macroeconomic variables.

The law of motion for the interest rate path $\left(i_{t}\right)$ assumes a standard monetary policy Taylor rule with an interest rate smoothing mechanism and monetary policy shock $\varepsilon_{t}^{i}$ :

$$
i_{t}=\phi_{i} i_{t-1}+\left(1-\phi_{i}\right)\left[\phi_{y} \hat{y}_{t}+\phi_{\pi}\left(\pi_{t}-\bar{\pi}\right)\right]+\varepsilon_{t}^{i} ; \varepsilon_{t}^{i} \sim i i d N\left(0, \varsigma_{i}^{2}\right) \text {. }
$$

This form of monetary policy represents the direct inflation-targeting strategy in which the central bank's main objective is to keep the inflation rate $\left(\pi_{t}\right.$; CPI) at its target level $(\bar{\pi})$. If this primary objective is met, then the interest rate is set in a way that will minimize the production volatility.

Theoretically, the inflation target is assumed to be zero. However, many central banks (including the Polish central bank, NBP) set their inflation targets as a positive number because of practical reasons, such as the possible upward bias in CPI (Unayama, 2004) or the fact that the optimal inflation rate in developed economies is reported to be around $1-3 \%$ (Khan and Senhadji, 2001). This is accounted for in the transformations applied to the inflation series in the empirical exercise of the current paper (Section 4).

The real effective exchange rate is assumed to follow the AR(1) process:

$$
q_{t}=\rho^{q} \cdot q_{t-1}+\varepsilon_{t}^{q} ; \varepsilon_{t}^{q} \sim i i d N\left(0, \varsigma_{q}^{2}\right) .
$$

The law of motion for the log deviation of the relative price between sectors from its steady state is the identity drawn directly from the definition of $S \equiv \frac{P^{A}}{P^{B}}$ : 


$$
\hat{s}_{t}=\hat{s}_{t-1}+\pi_{t}^{A}-\pi_{t}^{B}
$$

Finally, the model is closed with a set of identities related to the inflation rates, which are drawn from log-linearized price aggregators (Equations 10-12) and the definition of the real exchange rate (Equations 35-39):

$$
\begin{aligned}
& \pi_{t}=(1-n) \pi_{t}^{A}+n \pi_{t}^{B}, \\
& \pi_{t}^{H}=(1-n) \pi_{t}^{A, H}+n \pi_{t}^{B, H}, \\
& \pi_{t}^{A}=\pi_{t}^{A, H}+\frac{m}{1-m} \Delta q_{t}, \\
& \pi_{t}^{B}=\pi_{t}^{B, H}+\frac{m}{1-m} \Delta q_{t} .
\end{aligned}
$$

\section{Estimation Method}

In the empirical part of the current paper, the model is estimated using the IS curve (where the terms of trade are replaced with the real exchange rate using Equation (40) because of data availability):

$$
\hat{y}_{t}=E_{t}\left\{\hat{y}_{t+1}\right\}-\frac{1}{\sigma}\left(i_{t}-E_{t}\left\{\pi_{t+1}^{H}\right\}+\varepsilon_{t}^{p}\right)-\frac{m(v-1)}{\sigma(1-m)}\left(E_{t} \Delta q_{t+1}\right),
$$

together with Equations 65-73. The complete set of estimated equations is listed in Appendix 1.

The set of observable variables includes the following: the output gap $\left(\hat{y}_{t}\right)$; the inflation rate in sector $A\left(\pi_{t}^{A}\right)$; the inflation rate of consumer goods, excluding food and energy $\left(\pi_{t}^{B}\right)$; the real effective exchange rate $\left(\right.$ reer $\left._{t}\right)$; and the nominal interest rate $\left(i_{t}\right)$. The exogenous variables include the following:

- technology shock in sector $A: \varepsilon_{t}^{A} \sim$ iid $N\left(0, \varsigma_{A}^{2}\right)$,

- technology shock in sector $B: \varepsilon_{t}^{B} \sim$ iid $N\left(0, \varsigma_{B}^{2}\right)$,

- $\quad$ autoregressive (AR) preference shock: $\varepsilon_{t}^{p}=\rho_{p} \varepsilon_{t-1}^{p}+\zeta_{t}^{p}$ and $\zeta_{t}^{p} \sim i i d N\left(0, \varsigma_{p}^{2}\right)$,

- $\quad$ monetary policy shock $\varepsilon_{t}^{i} \sim$ iid $N\left(0, \varsigma_{i}^{2}\right)$ :

- $\quad$ REER shock: $\varepsilon_{t}^{q} \sim$ iid $N\left(0, \varsigma_{q}^{2}\right)$.

Note that the model consists of equations that contain a lagged dependent variable and those without such a variable, and the autoregression of the shock is present only in the latter. This means that there is an assumption of no persistence of the shocks 
where the autoregression is captured in an equation by the lagged term; that is, those shocks are driven only by the innovation terms. ${ }^{5}$ This step avoids the problem of a weak identification between the AR and moving average (MA) components of a process, as discussed in the empirical part of the present paper.

The estimation follows the Bayesian approach (An and Schorfheide, 2007). Unlike other estimation methods, such as the generalized method of moments or maximum likelihood estimation, the Bayesian approach allows estimating deep parameters' posterior density and including a priori information; the approach also allows formal model comparisons.

The joint distribution of the data $Y$ and the set of structural parameters $\Theta$ is obtained via the Bayes theorem (see, e.g., Herbst and Schorfheide, 2016, p. 29):

$$
P(\Theta \mid Y)=\frac{P(Y \mid \Theta) P(\Theta)}{P(Y)},
$$

where $P(\Theta \mid Y)$ is the posterior probability of the parameter set $\Theta$ given the dataset $Y$; $P(\Theta)$ is the a priori probability that is known before the model uses the data (i.e., before Bayesian updating); $P(Y \mid \Theta)$ is the likelihood function that summarizes the information about the parameters contained in the sample under analysis; and finally, $P(Y)$ denotes the marginal likelihood.

The first step of the estimation procedure is to solve the linear rational expectations model using the first-order approximation (Klein, 2000). The model is then written down in a state-space form where the observable variables are taken into account in the form of the measurement equations. Finally, the likelihood function is calculated given the parameter values. If the exogenous shock processes are assumed to be Gaussian, then the likelihood function can be evaluated using Kalman filtering (Herbst and Schorfheide, 2015 ).

In the final step, the posterior distribution is constructed using the random walk Metropolis-Hastings algorithm. ${ }^{6}$ The Bayesian framework offers a useful and formal tool for the model (Herbst and Schorfheide, 2015; Kass and Raftery, 1995). Let us define the model described in Section 2 as $M_{1}$. The model $M_{2}$ is then formulated by imposing

5 See Carrillo et al. (2007) for a discussion of the different ways to capture the persistence of a shock. I have run the robustness check regarding different assumptions, that is, considered a model with persistent technology shocks following $\mathrm{AR}(1)$ processes: $z_{t}^{A}=\alpha^{A} z_{t-1}^{A}+\varepsilon_{t}^{A}$ and $z_{t}^{B}=\alpha^{B} z_{t-1}^{B}+\varepsilon_{t}^{B} ; \varepsilon_{t}^{A} \sim$ iid $N\left(0, \varsigma_{A}^{2}\right)$ and $\varepsilon_{t}^{B} \sim$ iid $N\left(0, \varsigma_{B}^{2}\right)$. The Bayes factor does not discriminate between these two alternatives; however, the model with persistent shocks does not fulfil the convergence criteria for the $\mathrm{MH}$ algorithm. The results of this robustness check are available upon request.

6 The calculations are based on four random walk Metropolis-Hastings chains (of 100,000 draws each) with the initial $15 \%$ of draws discarded. All the steps described above are implemented in Dynare 4.5.3 for MATLAB. 
a restriction of homogenous price-setting mechanisms in both sectors $\left(\theta^{4}=\theta^{B}\right.$ and $\left.\omega^{A}=\omega^{B}\right)$. The model $M_{2}$ describes the same set of observable variables as $M_{1}$; it is also driven by the same exogenous variables but imposes the same level of nominal rigidities and inflation persistence across sectors. To evaluate the posterior probability of models $\mathrm{M}_{1}$ and $\mathrm{M}_{2}$ given the dataset $Y$, the Bayes factor is used:

$$
B_{12}=\frac{P\left(Y \mid \mathrm{M}_{1}\right)}{P\left(Y \mid \mathrm{M}_{2}\right)}
$$

where $P\left(Y \mid \mathrm{M}_{1}\right)=\int P\left(Y \mid \Theta_{1}, \mathrm{M}_{1}\right) P\left(\Theta_{1} \mid \mathrm{M}_{1}\right) d \Theta_{1}$ is the marginal data density associated with model $\mathrm{M}_{1}$. Bayes factoring is useful in evaluating the odds in favour of $\mathrm{M}_{1}$ :

$$
\frac{P\left(\mathrm{M}_{1} \mid Y\right)}{P\left(\mathrm{M}_{2} \mid Y\right)}=\frac{P\left(Y \mid \mathrm{M}_{1}\right)}{P\left(Y \mid \mathrm{M}_{2}\right)} \frac{P\left(\mathrm{M}_{1}\right)}{P\left(\mathrm{M}_{2}\right)} .
$$

Although it is assumed that $P\left(\mathrm{M}_{1}\right)=1-P\left(\mathrm{M}_{2}\right)$, this comparison is robust to model errors in the sense that even if all of the models under comparison are incorrectly specified, the model that is closest to the data-generating process will asymptotically receive a posterior probability equal to one (Fernández-Villaverde and Rubio-Ramirez, 2004).

The value of the Bayes factor, according to Kass and Raftery (1995), may be interpreted as the strength of the evidence against the null hypothesis of models $\mathrm{M}_{1}$ and $\mathrm{M}_{2}$ being equally good in describing the dataset $Y$. If the Bayes factor is between 1 and 3.2, then the evidence is negligible. Values from 3.2 to 10 and from 10 to 100 point to "substantial" and "strong" evidence, respectively. Finally, a Bayes factor value of over 100 represents decisive evidence against the null hypothesis, and it can be concluded that the model $\mathrm{M}_{1}$ describes the true data-generating process of $Y$.

\section{Data}

The estimation uses quarterly data for Poland from 1999 (Q1) to 2017 (Q4). The beginning of the sample is marked by the introduction of the direct inflation strategy (NBP, 1998). The output gap $\left(\hat{y}_{t}\right)$ is calculated as the percentage of the deviation in the gross domestic product (constant prices, seasonally adjusted) from its potential, which was approximated uisng Hodrick-Prescott (HP) filtered values.

The inflation rates in sectors $A$ and $B\left(\pi_{t}^{A}\right.$ and $\left.\pi_{t}^{B}\right)$ are expressed as the seasonally adjusted quarterly rates of change. The price indices in the respective sectors are "CPI: food and energy" and "CPI excluding food and energy," the latter of which is the most commonly referenced as a measure of core inflation. Both series were detrended using an HP filter, which served two purposes: removing trends in inflation rates connected to the period 
of strong disinflation and changes in the level of inflation target (1999-2002) and removing the mean from both series. Note that the theoretical model described in Section 2 was solved around a zero inflation steady state, whereas the monetary policy conducted by the NBP assumes a non-zero inflation target. The same transformation was applied to the measure of the nominal interest rate $\left(i_{t}\right)$ : Warsaw Interbank Offer Rate (WIBOR) $3 \mathrm{M}$. Finally, the HP-filtered values of the log real effective exchange rate for the Polish zloty (PLN) were used as $q_{i}$.

All the transformations are in line with the theoretical model assumptions, which state that all the variables enter the model as zero-mean deviations from the flexible-price steady state. Most authors agree that the filtering method may affect the results to some extent (e.g., Canova and Ferroni, 2011). Therefore, the results include a robustness check using two alternative methods of removing trends and means from the series: a onesided HP filter and a quadratic trend, ${ }^{7}$ which confirms the difference in the price-setting parameters (Appendix 2).

Figure 2: The Output Gap in Poland, 1999-2017

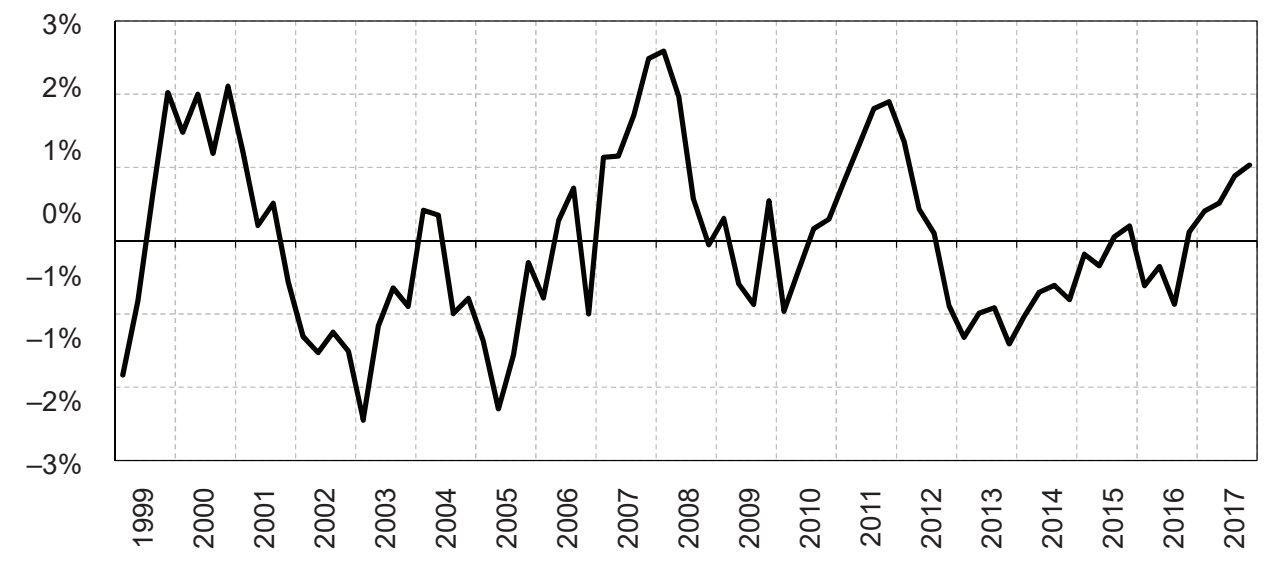

Source: Statistics Poland and the author's own calculations.

$7 \quad$ A one-sided HP filter was used to check whether the results are sensitive to the problems with efficiency at the end of the sample in a standard two-sided HP filter (see King and Rebelo, 1993). The quadratic trend was included because of the period of disinflation at the beginning of the sample. Kuchta (2014) used a similar transformation for Polish data. 
Figure 3: Inflation Rate in Poland, 1999-2017 (q-o-q, seasonally adjusted, HP filtered)

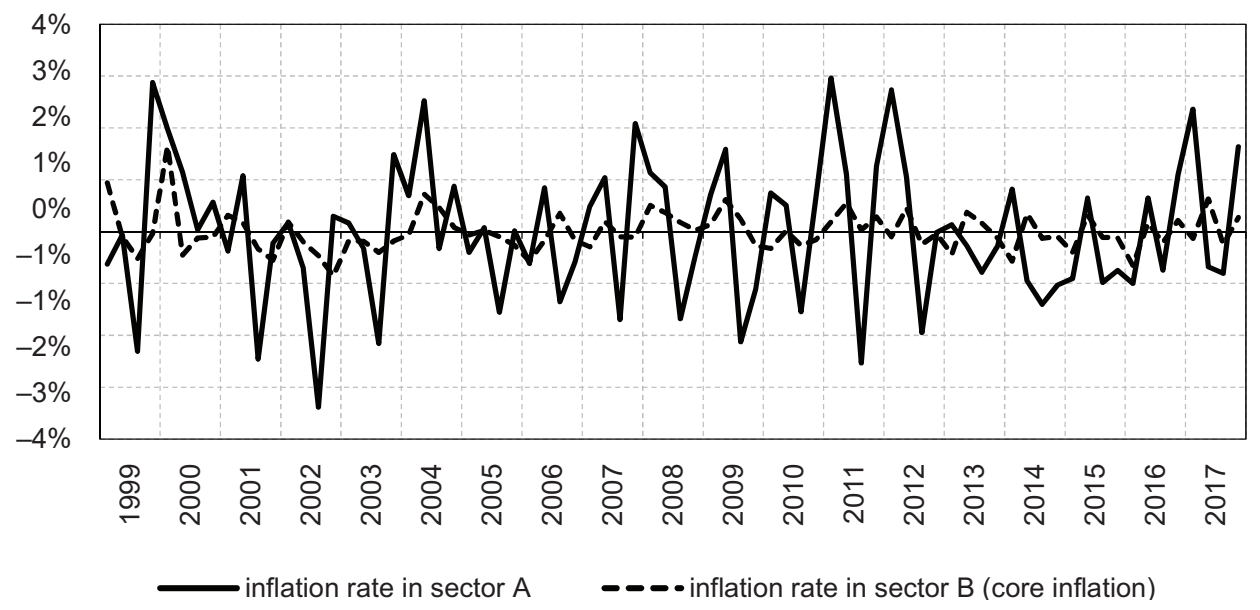

Source: Statistics Poland and the author's own calculations.

Figure 4 : Real Exchange Rate and Interest Rate (WIBOR 3M) in Poland, 1999-2017 (SA, HP filtered)

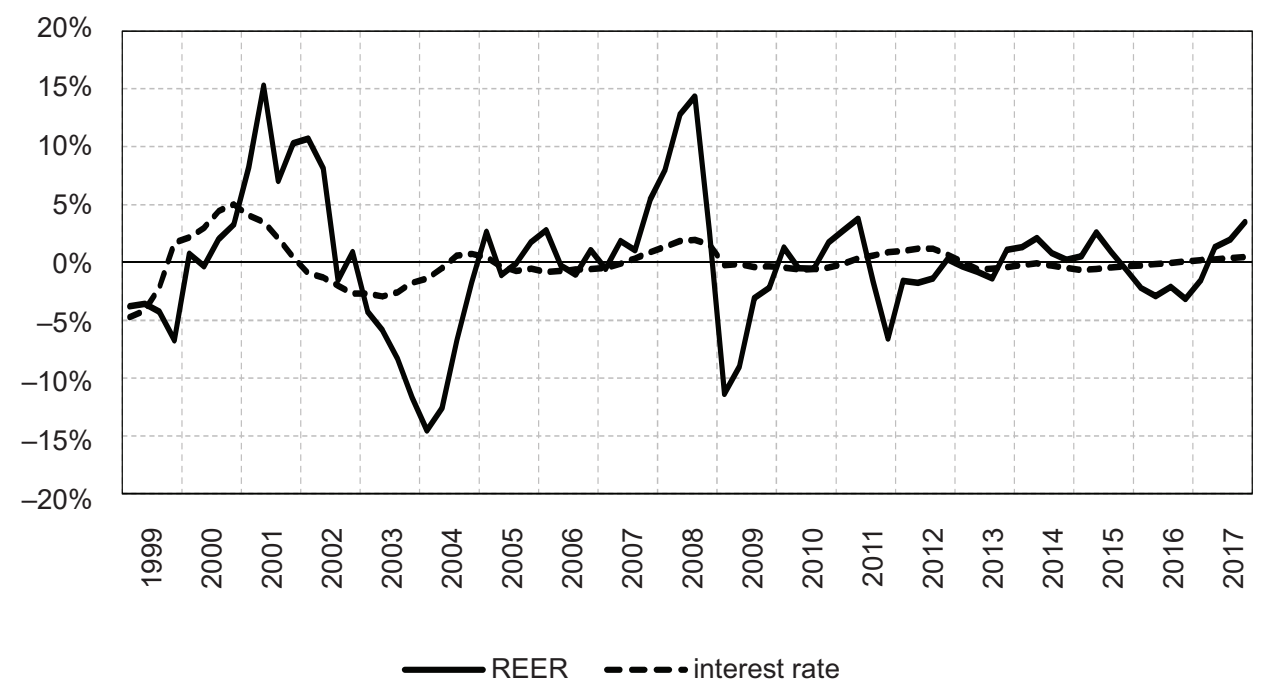

Source: Statistics Poland and the author's own calculations. 


\section{Results}

\subsection{Estimation results of the two-sector model}

This section presents the results of the Bayesian estimation of the two-sector model. First, the assumptions of the a priori distributions for each of the estimated parameters are stated (see Table 1). For the parameters that denote a Calvo probability level $\left(\theta^{B}, \theta^{B}\right)$ or a fraction of firms $\left(\omega^{A}, \omega^{B}\right)$, a beta distribution is assumed; this allows exclusion of any values that are inconsistent. The a priori distributions for those price-setting parameters are fairly agnostic (i.e., "loose priors") so as not to dominate the results with the assumptions. ${ }^{8}$ For the AR parameters $\left(\rho^{q}, \rho_{p}\right.$, and $\left.\phi_{i}\right)$, loose beta distributions are used as well. The shape of the distribution allows only a positive autoregression and ensures stationarity. These a priori distributions all have fairly high dispersion values but are not based on uniform distributions (a proposition made by Rabanal and Rubio-Ramirez, 2008). Instead, I follow Del Negro and Schorfheide's (2008) approach of using a distribution that drops sharply as the AR parameter gets very close to one. This prevents the a posteriori peaks with a parameter stuck in the upper region of the interval and is hence convenient from a computational point of view.

For the risk aversion $(\sigma)$ and Taylor rule parameters $\left(\phi_{\pi^{\prime}} \phi_{y}\right)$, gamma distributions are used, with the mean values set in a similar way as in the literature on Polish data (Baranowski and Szafrański, 2012; Kuchta, 2014; Baranowski, 2014). The a priori distribution of the shocks' standard deviations (SDs) in the model are inverse gamma distributions. The mean of each shock's SD was set to match the second moment of the variable directly affected by a given shock. The variance of the inverse gamma distribution for all of the SDs is not defined (i.e., the scale parameter equals 2), which is a standard assumption in the literature (see Adolfson et al., 2013; Smets and Wouters, 2003).

In the empirical exercise, some of the parameters in the theoretical model were calibrated because of a very weak identification (see Table 2). These parameters are as follows: the share of imported goods in the consumption basket $(m=0.2)$, which is equal to the average share of imports of goods and services in the gross output; the share of sector $B$ in consumption ( $n=0.6)$, which is equal to the weight of the core inflation in the CPI basket; and the elasticity of substitution between domestic and foreign goods $(\eta=1) .{ }^{9}$ The discount factor and the inverse of the Frisch elasticity value are calibrated following the literature.

$8 \quad$ Many researchers have used tight priors for $\theta$ and $\omega$, which are supported by microeconomic evidence (see Smets and Wouters, 2003).

9 The elasticity of a substitution equal to 1 is the equivalent of using the Cobb-Douglas function as a special case of the CES function in the aggregation scheme (see Equations (4) and (5)). 
Table 1: Estimated parameters in the two-sector model

\begin{tabular}{l|l|c|c|c|c|c}
\hline \multirow{2}{*}{ Parameter } & \multicolumn{3}{|c|}{ A priori distribution } & \multicolumn{2}{c}{ A posteriori distribution } \\
\cline { 2 - 7 } & Distribution type & Mean & SD & Mean & \multicolumn{2}{c}{$90 \%$ HPD interval' } \\
\hline $\boldsymbol{\sigma}$ & Gamma & 2.0 & 1.00 & 1.57 & 1.05 & 2.07 \\
\hline $\boldsymbol{\theta}^{A}$ & Beta & 0.5 & 0.25 & 0.69 & 0.60 & 0.79 \\
\hline $\boldsymbol{\theta}^{\boldsymbol{B}}$ & Beta & 0.5 & 0.25 & 0.95 & 0.90 & 0.99 \\
\hline $\boldsymbol{\omega}^{\boldsymbol{A}}$ & Beta & 0.5 & 0.25 & 0.12 & 0.01 & 0.23 \\
\hline $\boldsymbol{\omega}^{\boldsymbol{B}}$ & Beta & 0.5 & 0.25 & 0.24 & 0.07 & 0.40 \\
\hline$\phi_{\boldsymbol{i}}$ & Beta & 0.5 & 0.25 & 0.70 & 0.64 & 0.77 \\
\hline$\phi_{\boldsymbol{y}}$ & Gamma & 0.5 & 0.25 & 1.80 & 1.41 & 2.16 \\
\hline$\phi_{\boldsymbol{\pi}}$ & Gamma & 3.0 & 0.75 & 1.33 & 0.84 & 1.79 \\
\hline $\boldsymbol{\rho}^{q}$ & Beta & 0.5 & 0.25 & 0.80 & 0.67 & 0.93 \\
\hline $\boldsymbol{\rho}_{\boldsymbol{p}}$ & Beta & 0.5 & 0.25 & 0.85 & 0.77 & 0.93 \\
\hline $\boldsymbol{\varsigma}_{p}$ & Inverse gamma & 0.5 & $\infty^{*}$ & 0.96 & 0.73 & 1.17 \\
\hline $\boldsymbol{\varsigma}_{\boldsymbol{A}}$ & Inverse gamma & 1.0 & $\infty^{*}$ & 1.64 & 1.30 & 1.97 \\
\hline $\boldsymbol{\varsigma}_{\boldsymbol{B}}$ & Inverse gamma & 0.1 & $\infty^{*}$ & 0.76 & 0.62 & 0.89 \\
\hline $\boldsymbol{\varsigma}_{\boldsymbol{q}}$ & Inverse gamma & 0.1 & $\infty^{*}$ & 0.60 & 0.51 & 0.69 \\
\hline & 1.0 & $\infty^{*}$ & 3.57 & 3.09 & 4.04 \\
\hline
\end{tabular}

Note: ${ }^{1}$ HPD $=$ highest posterior density. ${ }^{*}$ The variance of the standard deviation is not defined (i.e., the scale parameter of the inverse gamma distribution equals 2 ).

Source: Author's own calculations

The former is a standard value $(\beta=0.99)$ that is used in a wide range of papers and implies a one-period steady-state nominal interest rate of 1\% (see Equation 31). The inverse Frisch elasticity value $(\varphi=2)$ is calibrated following Smets and Wouters (2003), who used this value as a starting point in their estimation because the value falls between the low estimates found in the microeconomic labour market literature and the relatively high estimates found in the macroeconomic literature. 
Table 2: Calibrated parameters in the two-sector model

\begin{tabular}{l|c}
\hline Parameter & Calibrated value \\
\hline Share of imported goods in the consumption basket $(\boldsymbol{m})$ & 0.2 \\
\hline Share of products from sector B in consumption basket $(\boldsymbol{n})$ & 0.6 \\
\hline Elasticity of substitution between domestic and foreign goods $(\boldsymbol{\eta})$ & 1 \\
\hline Discount factor $(\boldsymbol{\beta})$ & 0.99 \\
\hline Inverse of the Frisch elasticity $(\boldsymbol{\varphi})$ & 2 \\
\hline
\end{tabular}

Source: Author's own assumptions based on Statistics Poland, Smets and Wouters (2003), and Baranowski and Szafrański (2012).

A comparison of the a priori and a posteriori marginal densities (Figure 5 and Figure 6) shows that the dataset contains information that is valuable in the Bayesian updating process. The a posteriori marginal densities of all the estimated parameters are unimodal and have higher concentrations than the a priori densities.

Figure 5: Posterior Densities of Price-Setting Parameter Distributions
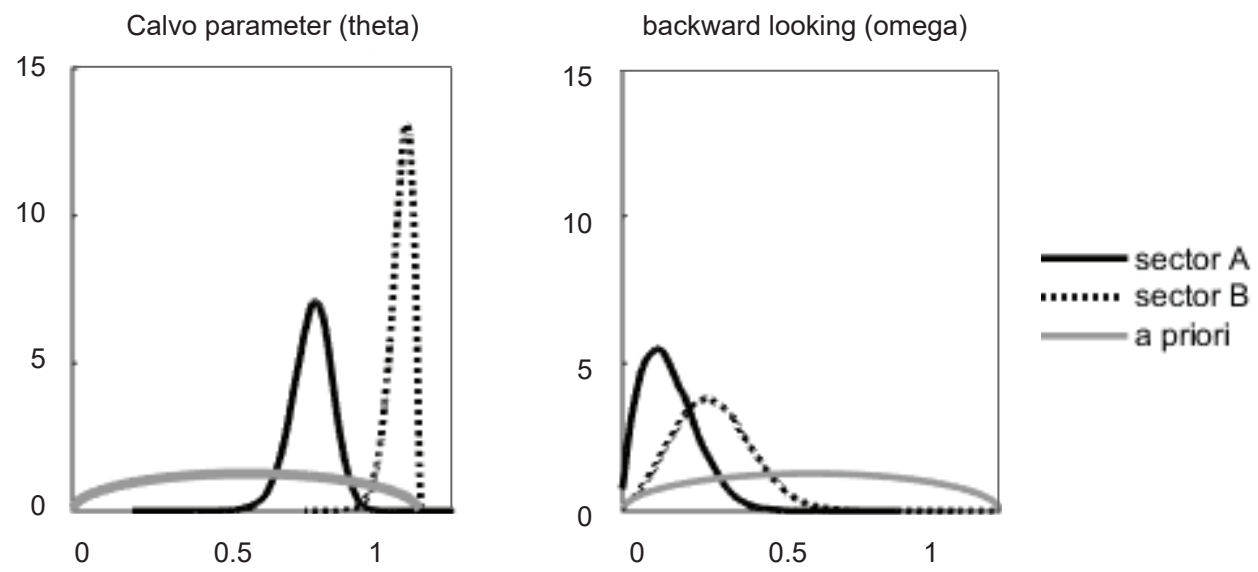

Source: Author's own calculations.

The current study shows strong evidence of sectoral price-setting heterogeneity in Poland. The Calvo parameters show that the price stickiness in sector $B$ is much higher than in sector $A$. The fraction of backward-looking firms is also higher in sector $B$, but the difference is much less pronounced. The higher price stickiness and the more 
backward-looking orientation of the price setting in sector $B$ (i.e., production of goods and services other than food and energy) together translate into a higher core inflation persistence. Several authors have empirically studied this phenomenon (see Bilke, 2005; Lünnemann and Mathä, 2004; Hertel and Leszczyńska, 2013).

Figure 6: Posterior Densities of Remaining Parameters' Distributions
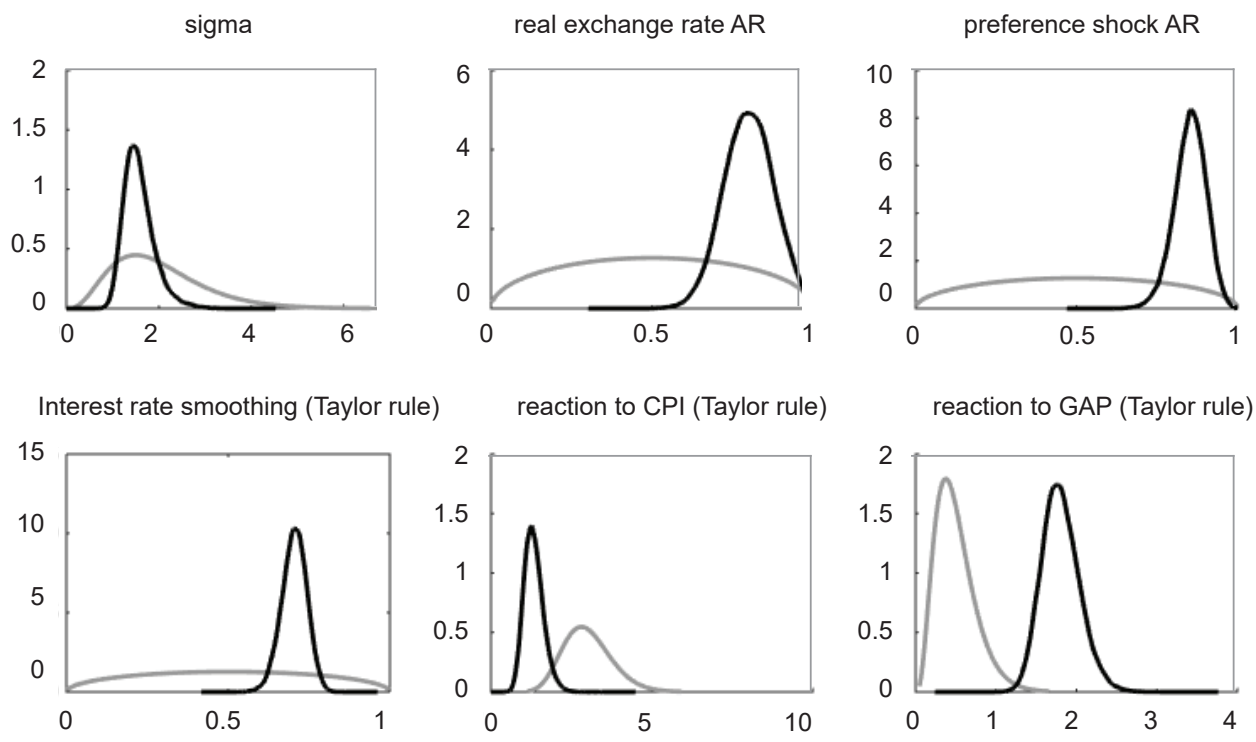

Source: Author's own calculations. Note: The black and gray lines are a posteriori and a priori distributions, respectively.

\subsection{Estimation Results of the One-Sector Model}

Table 3 presents the Bayesian estimates of the one-sector model $\mathrm{M}_{2}$, which was used to test whether the sectoral differences in the price-setting parameters are significant. The model $\mathrm{M}_{2}$ assumes the same a priori knowledge as the model $\mathrm{M}_{1}$, but adopts a restriction of equal price-setting parameters across sectors.

The results of the Taylor rule, sigma, and AR parameter estimates in the model $\mathrm{M}_{2}$ are close to those found in the model $\mathrm{M}_{1}$. The price-setting parameters' distributions lie in between the sectoral estimates in the model $\mathrm{M}_{1}$. To formally compare the models $\mathrm{M}_{1}$ and $\mathrm{M}_{2}$, the Bayes factor was calculated (Table 4). The a priori probability of each of the models being true is equal ( 0.5 for each $\mathrm{M})$. The Bayes factor is then calculated by comparing the respective marginal data densities. The value of 128.6 provides decisive evidence against the null hypothesis of the model $\mathrm{M}_{2}$ being equally as good as the model $\mathrm{M}_{1}$. 
Table 3: Estimated Parameters in the Model with Restrictions $\left(M_{2}\right)$

\begin{tabular}{|c|c|c|c|c|c|c|}
\hline \multirow{3}{*}{$\begin{array}{l}\text { Parameter } \\
\sigma\end{array}$} & \multicolumn{3}{|c|}{ A priori distribution } & \multicolumn{3}{|c|}{ A posteriori } \\
\hline & \multirow{2}{*}{$\begin{array}{l}\text { Distribution type } \\
\text { Gamma }\end{array}$} & \multirow{2}{*}{$\begin{array}{c}\text { Mean } \\
2.0\end{array}$} & \multirow{2}{*}{$\begin{array}{l}\text { SD } \\
1.00\end{array}$} & \multirow{2}{*}{$\begin{array}{c}\text { Mean } \\
1.69\end{array}$} & \multicolumn{2}{|c|}{$90 \%$ HPD interval } \\
\hline & & & & & 1.06 & 2.28 \\
\hline$\theta^{A}=\theta^{B}$ & Beta & 0.5 & 0.25 & 0.87 & 0.80 & 0.94 \\
\hline$\omega^{A}=\omega^{B}$ & Beta & 0.5 & 0.25 & 0.14 & 0.03 & 0.24 \\
\hline$\phi_{i}$ & Beta & 0.5 & 0.25 & 0.72 & 0.66 & 0.79 \\
\hline$\phi_{y}$ & Gamma & 0.5 & 0.25 & 1.88 & 1.45 & 2.29 \\
\hline$\phi_{\pi}$ & Gamma & 3.0 & 0.75 & 1.36 & 0.81 & 1.88 \\
\hline$\rho^{R E E R}$ & Beta & 0.5 & 0.25 & 0.80 & 0.66 & 0.94 \\
\hline$\rho_{p}$ & Beta & 0.5 & 0.25 & 0.82 & 0.73 & 0.90 \\
\hline$\varsigma_{B}$ & Inverse gamma & 0.5 & $\infty$ & 1.04 & 0.76 & 1.31 \\
\hline $\boldsymbol{\varsigma}_{A}$ & Inverse gamma & 1.0 & $\infty$ & 1.31 & 1.10 & 1.51 \\
\hline$\varsigma_{B}$ & Inverse gamma & 0.1 & $\infty$ & 0.89 & 0.72 & 1.05 \\
\hline $\boldsymbol{\varsigma}_{i}$ & Inverse gamma & 0.1 & $\infty$ & 0.60 & 0.51 & 0.69 \\
\hline$\varsigma_{q}$ & Inverse gamma & 1.0 & $\infty$ & 3.57 & 3.09 & 4.03 \\
\hline
\end{tabular}

Source: Author's own calculations.

Table 4: Comparison of the Models

\begin{tabular}{|c|c|c|c|}
\hline Model & A priori probability & Log-data density & Bayes factor \\
\hline $\begin{array}{l}M_{1} \\
\text { without restrictions } \\
\theta^{A} \neq \theta^{B} ; \omega^{A} \neq \omega^{B}\end{array}$ & $P\left(\mathrm{M}_{1}\right)=0.5$ & $\ln P\left(Y \mid M_{1}\right)=-638.8$ & \multirow{2}{*}{$B_{12}=\frac{P\left(Y \mid M_{1}\right)}{P\left(Y \mid M_{2}\right)}=128.6$} \\
\hline $\begin{array}{l}M_{2} \\
\text { with restrictions } \\
\theta^{A}=\theta^{B} ; \omega^{A}=\omega^{B}\end{array}$ & $P\left(\mathrm{M}_{2}\right)=0.5$ & $\ln P\left(Y \mid M_{2}\right)=-643.6$ & \\
\hline
\end{tabular}

Source: Author's own calculations in Dynare.

\subsection{Monetary policy implications}

The monetary policy implications of the presented model are based on the Bayesian impulse response functions (IRFs) of the main variables in the model: output gap, CPI, 
core inflation, and nominal interest rate. The focus is on the response to the monetary policy shock (Figure 7). The remaining shocks are presented in Appendix 3.

The figures represent a comparison of the IRFs calculated for the models $M_{1}$ (a model with heterogenous price-setting parameters) and $\mathrm{M}_{2}$ (a model with restrictions on these parameters). The IRFs for $M_{1}$ are presented using the mean of the parameters' posterior distribution together with the 90\% HPD intervals and represent the absolute deviations from the steady state in a log-linearized model. They are compared with the response of $\mathrm{M}_{2}$ based only on the mean of the posterior distribution (the HPD intervals are omitted for the sake of the clarity of the figures).

Figure 7: Response of the Main Variables to the Monetary Policy Shock $\left(\varepsilon_{t}^{i}\right)$
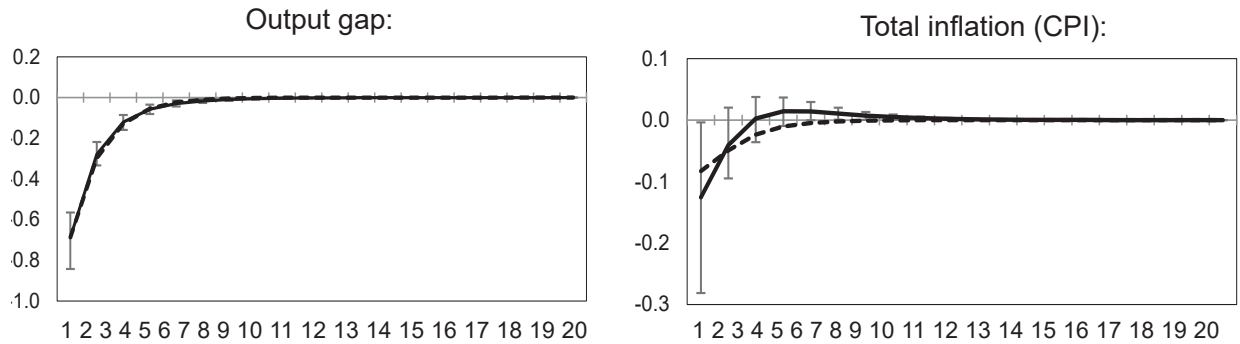

Core inflation:
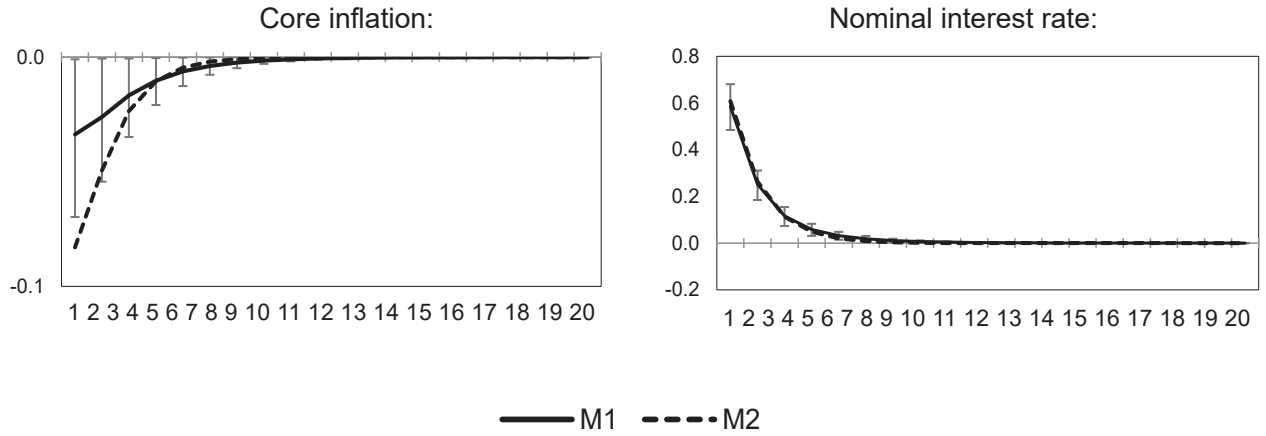

Note: The lines are based on the mean of the posterior distribution. The vertical lines around the response of $M 1$ mark the $90 \%$ HPD intervals.

Source: Author's own calculations.

The response of the output gap and inflation rates to the positive interest rate shock is in line with the economic intuition (a contractionary monetary policy shock lowers both the output and inflation rates). The remaining IRFs (see Appendix 3) are also consistent 
with similar simulations of the standard DSGE models. The preference shock that causes the households to increase the present consumption increases the output gap and causes the central bank to react by raising the interest rate (Figure 9). Negative technology shocks (e.g., a drop in labour productivity) in both sectors increase the prices (Figures 10 and 11). The monetary authority reacts to this by raising the interest rate, which lowers the output below the steady-state level.

The comparison of the IRFs from the models $\mathrm{M}_{1}$ and $\mathrm{M}_{2}$ shows that the heterogeneous model generates less variance regarding the core inflation to the monetary policy shock. However, this comparison should be treated with caution because the assumptions of these two models are counterfactual in the sense that only one of the models can be true. The analysis based on the Bayes factor (see Table 4) shows that the sectoral differences in the price-setting mechanisms in Poland are statistically significant. Therefore, using a one-sector model as a tool for analyzing the economy may lead to a systematic bias. For example, the response of the core inflation to the monetary policy shock can be overestimated. Similarly, the response of the inflation and interest rates to the technology shock in the food and energy sector may in fact be lower than what a one-sector model shows (see Figure 10 in Appendix 3).

\section{Conclusions}

The aim of the paper was to develop a theoretical model suitable for the analysis of pricesetting heterogeneity in a small open economy. The model is based on the existing work of Benigno and López-Salido (2006) and is one of many examples of a DSGE model that utilizes heterogeneous price stickiness (e.g., Aoki, 2001; Bodenstein et al., 2008). The model allows analyses of a small open economy by extending the existing multisector models by using the mechanisms described by Galí and Monacelli (2005). As a result, the model enables monetary policy analyses that take into account existing sectoral differences in price-setting mechanisms found in an open economy.

In the second part of the paper, the model was estimated using Polish data. Using Bayesian techniques, it is shown that the period from 1999 to 2017 saw significant differences in price stickiness and inflation persistence in the sectors that produce food and energy compared with the sectors that produce other goods and services. The results of the estimation of the macroeconomic model are in line with what the little microeconomic evidence has found, showing that the prices of food and energy are much less sticky than the prices of other goods and services. These differences may influence the results of policy analyses made using the DSGE models. The analysis of the IRFs shows that ignoring the sectoral heterogeneity (i.e., using a one-sector model as a tool 
for policy analysis) leads to a significant bias in assessing the inflation and interest rate responses to shocks affecting the economy.

The present study opens up several areas for further investigation. In particular, the model utilizes a standard, time-invariant Taylor rule, but the period under investigation covered the introduction of Poland's central bank's forward guidance. The role of core inflation on monetary policy decisions could also be investigated directly by using a Taylor rule that places a larger weight on this inflationary measure. The model is also suitable for analyses of sectoral shocks affecting different measures of inflation (see Hałka and Szafrański, 2018, for a multi-level factor model approach to this problem).

\section{Appendix 1. Model Summary}

The estimation is based on the following equations:

$$
\begin{aligned}
& \hat{y}_{t}=E_{t}\left\{\hat{y}_{t+1}\right\}-\frac{1}{\sigma}\left(i_{t}-E_{t}\left\{\pi_{t+1}^{H}\right\}+\varepsilon_{t}^{p}\right)-\frac{m(v-1)}{\sigma(1-m)}\left(E_{t} \Delta q_{t+1}\right) \\
& \pi_{t}^{A, H}=\lambda^{A}(\varphi+\sigma) \hat{y}_{t}-n \lambda^{A}(\varphi+1) \hat{s}_{t}+\gamma_{1}^{A} E_{t}\left\{\pi_{t+1}^{A, H}\right\}+\gamma_{2}^{A} \pi_{t-1}^{A, H}+\varepsilon_{t}^{A} \\
& \pi_{t}^{B, H}=\lambda^{B}(\varphi+\sigma) \hat{y}_{t}+(1-n) \lambda^{B}(\varphi+1) \hat{s}_{t}+\gamma_{1}^{B} E_{t}\left\{\pi_{t+1}^{B, H}\right\}+\gamma_{2}^{B} \pi_{t-1}^{B, H}+\varepsilon_{t}^{B} \\
& i_{t}=\phi_{i} i_{t-1}+\left(1-\phi_{i}\right)\left[\phi_{y} \hat{y}_{t}+\phi_{\pi} \pi_{t}\right]+\varepsilon_{t}^{i} ; \varepsilon_{t}^{i} \sim \operatorname{iid} N\left(0, \varsigma_{i}^{2}\right) \\
& q_{t}=\rho^{q} * q_{t-1}+\varepsilon_{t}^{q} ; \varepsilon_{t}^{q} \sim \text { iid } N\left(0, \varsigma_{q}^{2}\right) \\
& \hat{s}_{t}=\hat{s}_{t-1}+\pi_{t}^{A}-\pi_{t}^{B} \\
& \pi_{t}=(1-n) \pi_{t}^{A}+n \pi_{t}^{B} \\
& \pi_{t}^{H}=(1-n) \pi_{t}^{A, H}+n \pi_{t}^{B, H} \\
& \pi_{t}^{A}=\pi_{t}^{A, H}+\frac{m}{1-m} \Delta q_{t} \\
& \pi_{t}^{B}=\pi_{t}^{B, H}+\frac{m}{1-m} \Delta q_{t}
\end{aligned}
$$




\section{Appendix 2. Robustness Check - Filtering the Dataset}

Figure 8: Robustness Check Using Different Methods for Filtering the Data

quadratic trend

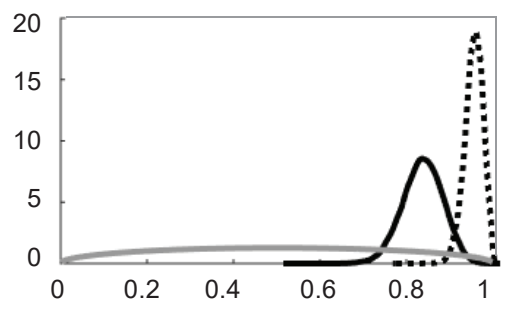

quadratic trend

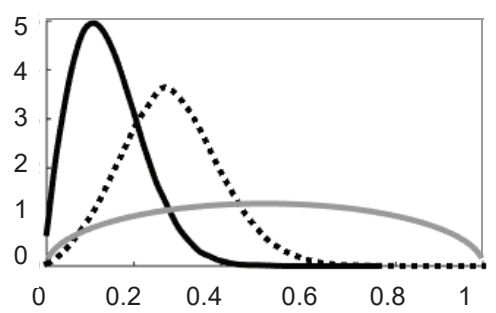

one sided HP filter

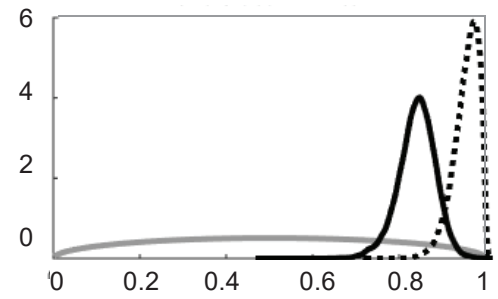

one sided HP filter

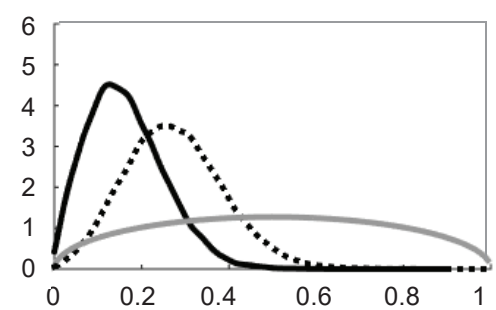

theta $\mathrm{A} \quad=-=$ theta $\mathrm{B} \rightleftharpoons$ a priori

Source: Author's own calculations.

\section{Appendix 3. Impulse Response Functions}

Figure 9: Response of the main variables to the preference shock $\left(\zeta_{t}^{p}\right)$

Output gap:

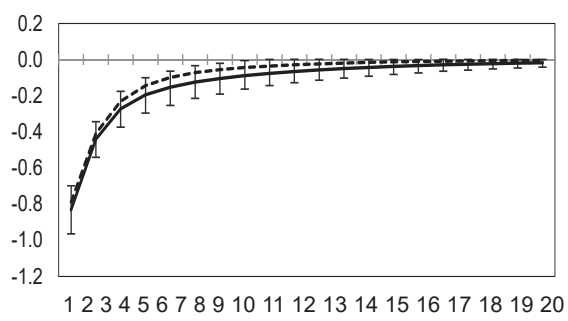

Total inflation (CPI):

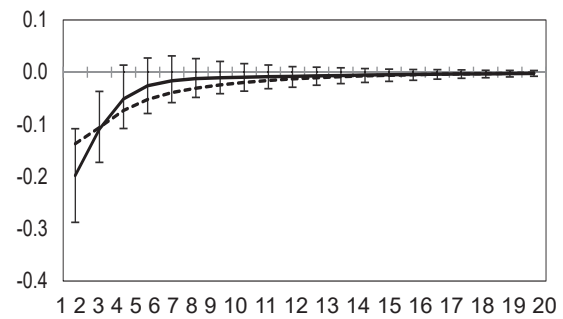

$\longrightarrow M 1-\cdots M 2$ 
Core inflation:

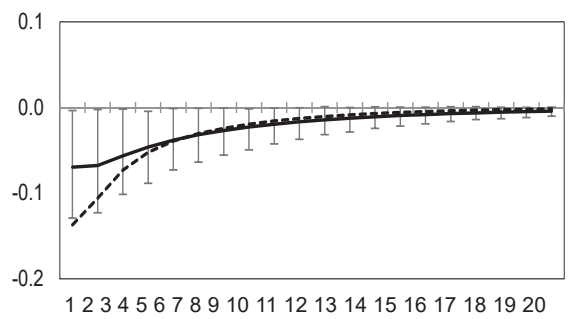

Nominal interest rate:

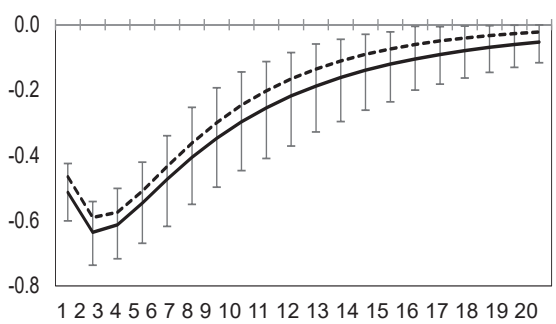

M1 -.-.-M2

Note: The lines are based on the mean of the posterior distribution. Vertical lines around the response of $M_{1}$ mark the $90 \%$ HPD intervals.

Source: Author's own calculations.

Figure 10: Response of the Main Variables to the Technology Shock in Sector $A\left(\varepsilon_{t}^{A}\right)$

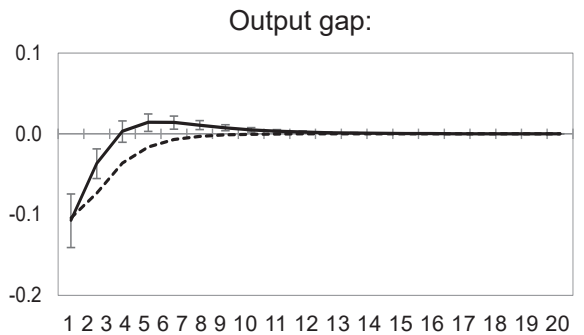

Core inflation:

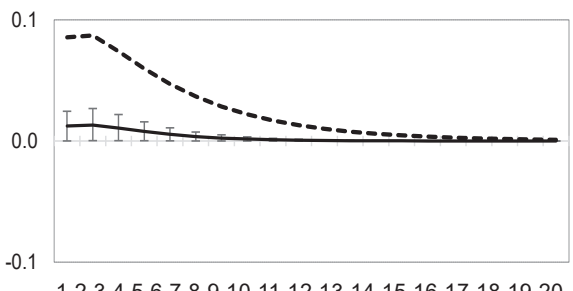

Total inflation (CPI):

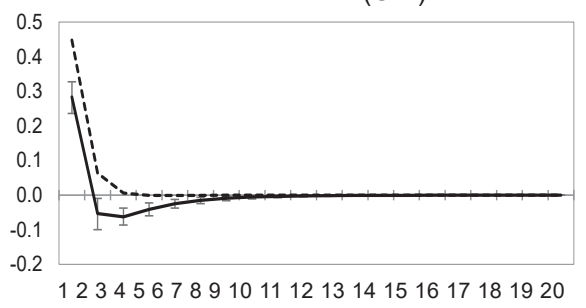

Nominal interest rate:

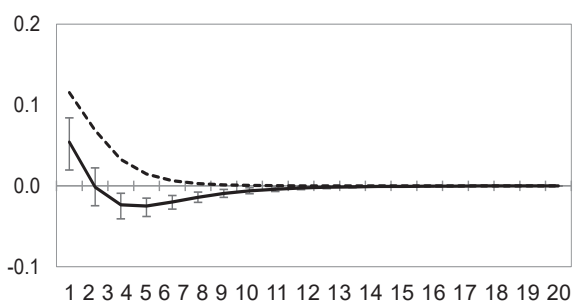

-M1 $\quad \cdots M 2$

Note: The lines are based on the mean of the posterior distribution. The vertical lines around the response of $M_{1}$ mark the $90 \%$ HPD intervals.

Source: Author's own calculations. 
Figure 11: Response of the Main Variables to the Technology Shock in Sector $B\left(\varepsilon_{t}^{B}\right)$

Output gap:

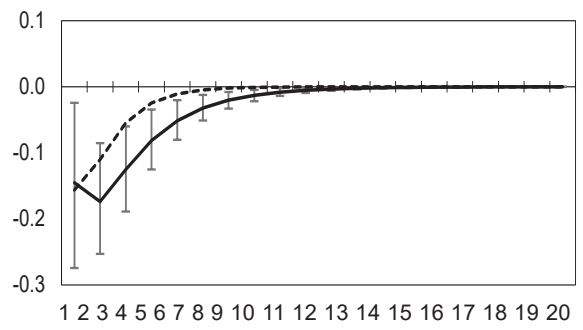

Core inflation:

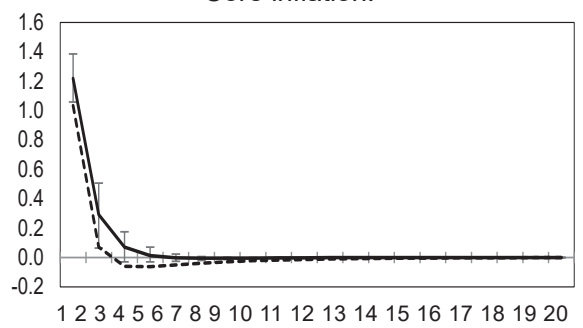

Total inflation (CPI):

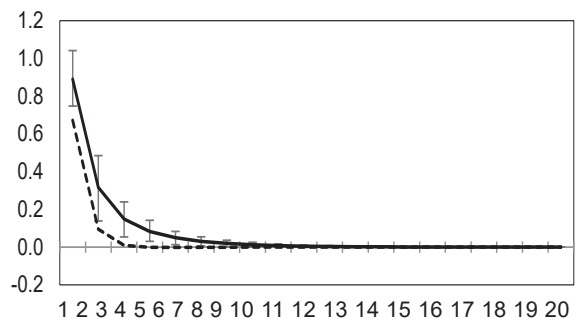

Nominal interest rate:

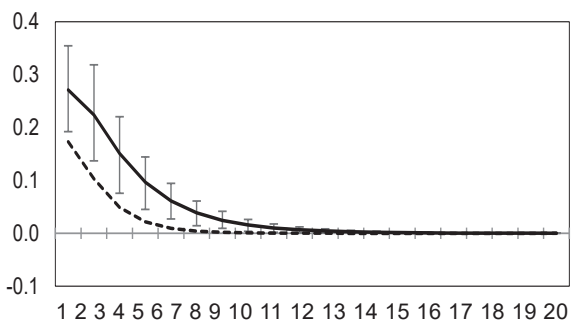

$\longrightarrow M 1 \quad-\cdots M 2$

Note: The lines are based on the mean of the posterior distribution. The vertical lines around the response of $M_{1}$ mark the $90 \%$ HPD intervals.

Source: Author's own calculations.

\section{References}

Adolfson, M., Laséen, S., Christiano, L., Trabandt, M., Walentin, K. (2013). Ramses II - Model Description. Sveriges Riksbank. Occasional Paper Series No. 12.

An, S., Schorfheide, F. (2007). Bayesian Analysis of DSGE Models. Econometric Review, 26(2-4), 113-172, https://doi.org/10.1080/07474930701220071

Aoki, K. (2001). Optimal Monetary Policy Responses to Relative-Price Changes. Journal of Monetary Economics, 48(1), 55-80, https://doi.org/10.1016/s0304-3932(01)00069-1

Baranowski, P. (2014). Reguły Polityki Pieniężnej w Polsce. Podejście llościowe (English). Łódź: Wydawnictwo Uniwersytetu Łódzkiego. ISBN 978-83-7969-070-1.

Baranowski, P., Szafrański, G. (2012). Effects of Monetary Policy in a Small-Scale DSGE Model for Poland - How Much the Estimation Methods Determine the Results? Bank i Kredyt, 43(4), 119-144. 
Benigno, P. (2004). Optimal Monetary Policy in a Currency Area. Journal of International Economics, 63(2), 293-320, https://doi.org/10.1016/S0022-1996(03)00055-2

Benigno, P., López-Salido, D. J. (2006). Inflation Persistence and Optimal Monetary Policy in the Euro Area. Journal of Money, Credit and Banking, 38(3), 587-614, https://doi. org/10.1353/mcb.2006.0038

Bilke, L. (2005). Break in the Mean and Persistence of Inflation: A Sectoral Analysis of French CPI. Banque de France. Working Paper No. 122, https://doi.org/10.2139/ssrn.1706095

Bils, M., Klenow, P. J. (2004). Some Evidence on the Importance of Sticky Prices. Journal of Political Economy, 112(5), 947-985, https://doi.org/10.1086/422559

Bodenstein, M., Erceg, C. J., Guerrieri, L. (2008). Optimal Monetary Policy with Distinct Core and Headline Inflation Rates. Journal of Monetary Economics, 55, 18-33, https://doi. org/10.1016/j.jmoneco.2008.07.010

Canova, F., Ferroni, F. (2011). Multiple Filtering Devices for the Estimation of Cyclical DSGE Models. Quantitative Economics, 2(1), 73-98, https://doi.org/10.3982/QE36

Carrillo, J., Fève, P., Matheron, J. (2007). Monetary Policy Inertia or Persistent Shocks: A DSGE Analysis. International Journal of Central Banking, 3(2), 1-38.

Clarida, R., Galí, J., Gertler, M. (2001). Optimal Monetary Policy in Open versus Closed Economies: An Integrated Approach. The American Economic Review, 91(2), 248-252, https://doi.org/10.1257/aer.91.2.248

Del Negro M., Schorfheide, F. (2008). Forming Priors for DSGE Models (and How it Affects the Assessment of Nominal Rigidities). Journal of Monetary Economics, 55(7), 1191-1208, https://doi.org/10.1016/j.jmoneco.2008.09.006

Dhyne, E., Álvarez, L. J., Le Bihan, H., Veronese, G., Dias, D., Hoffmann, J., Jonker, N., Lünnemann, P., Rumler, F., Vilmunen, J. (2006). Price Changes in the Euro Area and the United States: Some Facts from Individual Consumer Price Data. Journal of Economic Perspectives, 20(2), 171-192, https://doi.org/10.1257/jep.20.2.171

Fernández-Villaverde, J., Rubio-Ramirez, J. F. (2004). Comparing Dynamic Equilibrium Models to Data: A Bayesian Approach. Journal of Econometrics, 123(1), 153-187, https://doi. org/10.1016/j.jeconom.2003.10.031

Galí, J. (2008). Monetary Policy, Inflation and the Business Cycle. Princeton, New Jersey, USA: Princeton University Press. ISBN 978-0-691-13316-4.

Galí, J., Gertler, M. (1999). Inflation Dynamics: A Structural Econometric Analysis. Journal of Monetary Economics, 44(2), 195-222, https://doi.org/10.1016/S0304-3932(99)00023-9

Galí, J., Monacelli, T. (2005). Monetary Policy and Exchange Rate Volatility in a Small Open Economy. Review of Economic Studies, 72(3), 707-734, https://doi. org/10.1111/j.1467-937X.2005.00349.x

Hałka, A., Szafrański, G. (2018). What Common Factors Are Driving Inflation in CEE Countries? Prague Economic Papers, 27(2), 131-148, https://doi.org/10.2139/ssrn.2805891

Herbst, E. P., Schorfheide, F. (2015). Bayesian Estimation of DSGE Models. Princeton, New Jersey, USA: Princeton University Press. ISBN 978-0-691-16108-2. 
Hertel, K., Leszczyńska, A. (2013). Inflation Persistence at Disaggregated Level - Empirical Study for Poland. Przegląd Statystyczny, 2, 187-209.

Kass, R., Raftery, A. (1995). Bayes Factors. Journal of the American Statistical Association, 90(430), 773-795, https://doi.org/10.1080/01621459.1995.10476572

Khan, M., Senhadji, S. (2001). Threshold Effects in the Relationship between Inflation and Growth: An Overview. IMF Staff Papers, 48(1).

King, R. G., Rebelo, S. T. (1993). Low Frequency Filtering and Real Business Cycles. Journal of Economic Dynamics and Control, 17(1-2), 207-231, https://doi.org/10.1016/ S0165-1889(06)80010-2

Klein, P. (2000). Using the Generalized Schur Form to Solve a Multivariate Linear Rational Expectations Model. Journal of Economic Dynamics and Control, 24(10), 1405-1423, https://doi.org/10.1016/s0165-1889(99)00045-7

Kuchta, Z. (2014). Nominal Wage Rigidities in Small Scale DSGE Models: An Empirical Analysis for Poland. Gospodarka Narodowa, 274(6), 31-56, https://doi.org/10.33119/ gn/100874

Lünnemann, P., Mathä, T. (2004). How Persistent Is Disaggregate Inflation? An Analysis Across EU15 Countries and HICP Sub-Indices. ECB. Working Paper Series No. 415.

Macias, P., Makarski, K. (2013). Stylizowane Fakty o Cenach Konsumenta w Polsce (English). Narodowy Bank Polski. Materiały i Studia NBP No. 295.

NBP (1998). Medium-Term Strategy of Monetary Policy. Warsaw: Narodowy Bank Polski.

Obstfeld, M., Rogoff, K. (2000). New Directions for Stochastic Open Economy Models. Journal of International Economics, 50(1), 117-153, https://doi.org/10.1016/ s0022-1996(99)00034-3

Rabanal, P., Rubio-Ramirez, J. F. (2008). Comparing New Keynesian Models in the Euro Area: A Bayesian Approach. Spanish Economic Review, 10(1), 23-40, https://doi.org/10.1007/ s10108-007-9031-5

Smets, F., Wouters, R. (2003). An Estimated Dynamic Stochastic General Equilibrium Model of the Euro Area. Journal of the European Economic Association, 1(5), 1123-1175, https://doi.org/10.1162/154247603770383415

Unayama, T. (2004). Upward Bias in the Consumer Price Index under the ZeroInflation Economy. Economic Letters, 85(1), 139-144, https://doi.org/10.1016/j. econlet.2004.03.028

Walsh, C. E. (2010). Monetary Theory and Policy. Cambridge, Massachusetts: MIT Press. ISBN 978-0-262-01377-2.

Wickens, M. (2008). Macroeconomic Theory. Princeton, New Jersey, USA: Princeton University Press. ISBN 978-0-691-11640-2. 